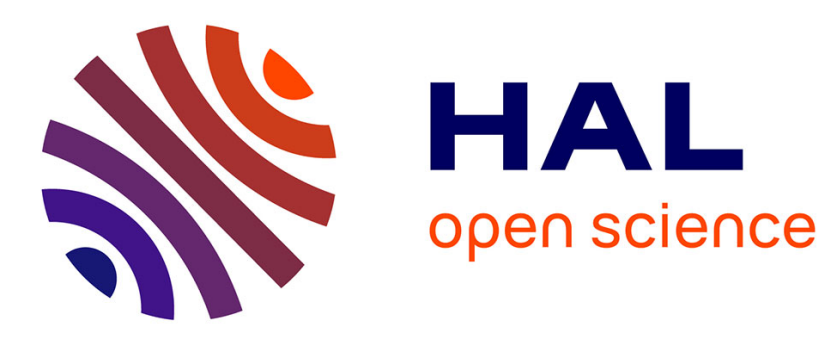

\title{
Simulation of the 2004 tsunami of Les Saintes in Guadeloupe (Lesser Antilles)
}

Louise Cordrie, Javier Escartin, Audrey Gailler, Nathalie Feuillet, Philippe Heinrich

\section{- To cite this version:}

Louise Cordrie, Javier Escartin, Audrey Gailler, Nathalie Feuillet, Philippe Heinrich. Simulation of the 2004 tsunami of Les Saintes in Guadeloupe (Lesser Antilles). OCEANS 2019 - Marseille, Jun 2019, Marseille, France. pp.1-9, 10.1109/OCEANSE.2019.8867447 . hal-02332675

\section{HAL Id: hal-02332675 \\ https://hal.science/hal-02332675}

Submitted on 19 Oct 2021

HAL is a multi-disciplinary open access archive for the deposit and dissemination of scientific research documents, whether they are published or not. The documents may come from teaching and research institutions in France or abroad, or from public or private research centers.
L'archive ouverte pluridisciplinaire HAL, est destinée au dépôt et à la diffusion de documents scientifiques de niveau recherche, publiés ou non, émanant des établissements d'enseignement et de recherche français ou étrangers, des laboratoires publics ou privés. 


\title{
Simulation of the 2004 tsunami of Les Saintes in Guadeloupe (Lesser Antilles) using new source constraints
}

Louise Cordrie • Audrey Gailler • Javier

Escartin • Nathalie Feuillet • Philippe Heinrich

Received: date / Accepted: date

\begin{abstract}
The arc of the Lesser Antilles is associated with a significant tectonic activity due to the subduction of the Atlantic oceanic plate under the Caribbean plate. Earthquakes in this context have the potential to trigger landslides and tsunamis due to the important vertical seafloor displacement. The historical tsunamigenic earthquakes in this region are rare, but the damages they may have generated before along the coasts show that they pose a considerable threat to the closest inhabited islands. The most recent tsunamigenic earthquake occurred in 2004 in the area of Les Saintes, along a normal fault system located in the back-arc of the subduction. This $\mathrm{Mw}=6.3$ earthquake generated small waves with $2 \mathrm{~m}$ of run-up in several bays of Les Saintes, a group of islands in the South of Guadeloupe. A recent survey conducted in the source area using deep-sea vehicles revealed for the first time an important coseismic slip on the Roseau fault plane, attributed to the 2004 event, which had not been predicted in the seismic inversion models. This event and the data-set on the Roseau fault gives the opportunity to model precisely the earthquake, to compare the simulation results with the observations and to evaluate the impact of the rupture heterogeneity and rupture shallowness on the height of the tsunami waves. Extending our earlier work (Cordrie et al., 2019) and in order to avoid a loss of quality from the data-set in the modeling of the initial sea-surface deformation especially in shallow depth and near field context, a transfer function of the deformation from the seafloor to the sea-surface and different numerical schemes were used. Re-

L. Cordrie

CEA, DAM, DIF, F-91297 Arpajon, France. Tel.: +33678528925

E-mail: louise.cordrie@gmail.com or louise.cordrie@cea.fr

A. Gailler

CEA, DAM, DIF, F-91297 Arpajon, France.

J. Escartin

Institut de Physique du Globe de Paris, 75238 Paris, France. Now at Laboratoire de Géologie, UMR 8538, Ecole Normale Supérieure, PSL Research University, CNRS, Paris, France

N. Feuillet

Institut de Physique du Globe de Paris, 75238 Paris, France

P. Heinrich

CEA, DAM, DIF, F-91297 Arpajon, France.
\end{abstract}


sults on the tsunami height distribution indicate some local tsunami amplification phenomena linked to the bathymetry or the coast-line geometry and highlight the most endangered areas of the islands. The simulations give additional constraints on the source, show the impact of the slip heterogeneities on the tsunami and finally provide a complementary estimation of the 2004 coseismic slip intensity.

Keywords tsunami $\cdot$ earthquake $\cdot$ source $\cdot$ model

\section{Introduction}

On the morning of the 21st of November 2004, at 11:41 UTC (07:41 local time), a magnitude 6.3 earthquake occurred offshore in the Dominica Passage, between the islands of Les Saintes and Dominica. The earthquake (Beauducel et al., 2005; Feuillet et al., 2011a; Bazin et al., 2010) ruptured the Roseau fault (Leclerc et al., 2016; Feuillet et al., 2011), an active NE-dipping normal fault. It was followed by several Mw 5 aftershocks a few hours and a few days after (Feuillet et al., 2011a), many of which have been felt by the inhabitants of the closest islands. The main shock reached an intensity of VIII in Les Saintes causing severe damages locally and generated a small tsunami that was observed at different places on the island's coast (Zahibo et al., 2005; Le Friant et al., 2008). Since the '80s, this area experienced another $\mathrm{M}>6.0$ earthquake close to Redonda Island $(\mathrm{Mw}=6.3)$ in 1985 (Landers et al., 2002; Shepherd and Lynch, 1992) that caused a several-centimeter tsunami at Basse-Terre, Guadeloupe. The 2004 earthquake is one of the strongest earthquakes felt in the French territory, with the Martinique one, $\mathrm{Mw}=7.1$, that occurred in November 2007. It is also only the fifth tsunamigenic earthquake in the known historical tsunami catalog of the Lesser Antilles (Fig. 1).

The occurrence of a tsunami was not necessarily expected considering the magnitude of the earthquake but the shallowness of the hypocenter $(10 \mathrm{~km} \mathrm{deep})$ and the strong normal component of fault mechanism are two characteristics favorable to the initiation of a tsunami wave. The Roseau Fault was recently mapped during the 2013 ODEMAR cruise (doi:10.17600/13030070) and the 2017 SUBSAINTES cruise (doi:10.17600/17001000) with both shipboard mapping, and deployment of deep-sea vehicles for high-resolution, near-bottom bathymetric and optical surveys. It revealed an important fault scarp with traces of a coseismic slip with a maximum displacement exceeding 2.5m (Escartin et al., 2019 - EGU ABSTRACT) corresponding to the 2004 event. Shallow submarine earthquakes whose associated coseismic slip was imaged are very few. Some submarine fault scarps have already been identified and associated with the coseismic slip of old events but the lack of seismic data does not enable a precise study of the rupture processes (Armijo et al., 2005; Matsumoto et al., 2009; Tsuji et al., 2012). As well, campaigns of reactivated faults mapping have been done for some large events such as the Tohoku-Oki earthquake (Fujiwara et al., 2011; Kodaira et al., 2012) but it implies very different and specific seafloor vertical displacements. The opportunity of having both seismic data, tsunami observations, and coseismic slip enables an interesting analysis of the contributions and the flaws of the different methods (seismic inversion, tsunami simulation, tectonic models...) in the process of identifying the earthquake source parameters. Among them, tsunami simulations bring additional constraints on some of the parameters, here we revisited the models performed earlier (Cordrie et al., 2019) by focusing on the slip intensity 
and the heterogeneity of the source and we present the further contribution of the 2004 tsunami models to a better understanding of this kind of event in the Lesser Antilles.

Tsunami models are generally computed with simple Okada source models where the initial sea-surface displacement corresponds to the seafloor Okada displacement. The important dispersion effect of the water mass, the shallow rupture, and the thickness of the water layer are conditions (reunited for the 2004 Les Saintes earthquake) that question the validity of this initial sea-surface displacement assumption. We present in this article a version of the tsunami simulation code adapted to such a shallow fault model, to maximize the use of the fault rupture high-resolution data and to show the impact of such level of resolution on simulation results. The bathymetric and topographic grids used for modeling the tsunami along the coast of Les Saintes, Marie-Galante and Guadeloupe are coming from a 100m resolution bathymetric data set (MNT Bathymétrique de la façade Atlantique, http://dx.doi.org/10.17183/ MNT_ATL100m_HOMONIM_WGS84, SHOM 2015 (Projet Homonim)) and a 5m resolution Litto3D survey (SHOM, LITTO3D Guadeloupe 2016, https://diffusion.shom. fr/media/wysiwyg/pdf/Specifications-techniques-Litto3D_v1_0-Doc_v1_5.pdf). This high-resolution enables an evaluation of the most endangered places, with runup modeling, and an analysis of local phenomenon (amplification, resonances) associated to specific bathymetric or topographic features.
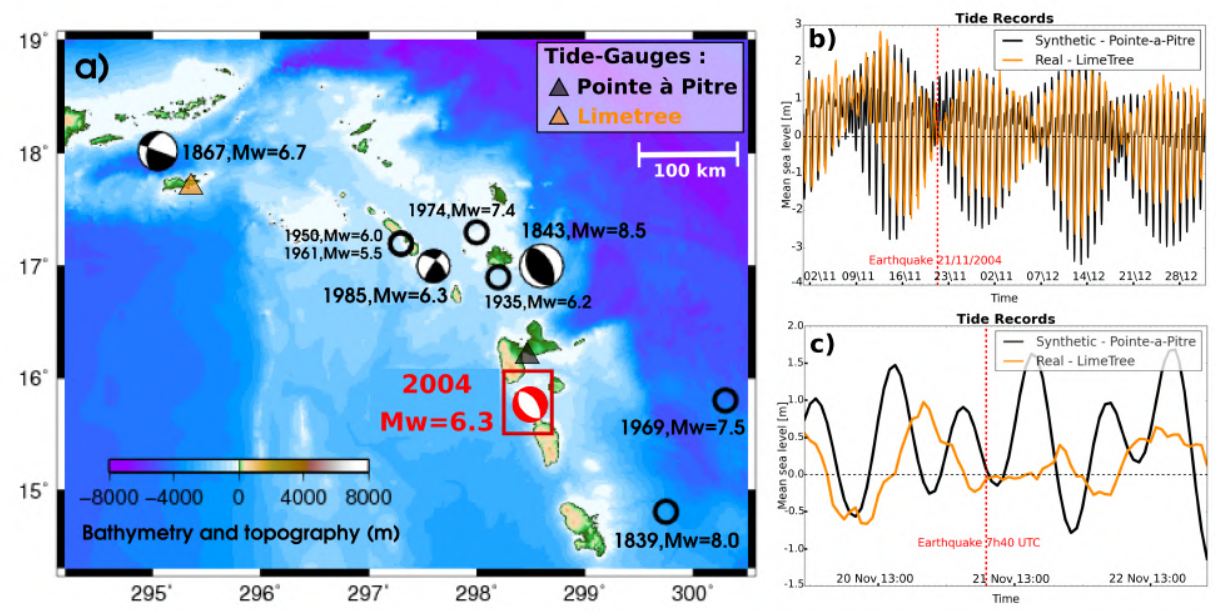

Fig. 1 a) Map of the historical seismicity of the Lesser Antilles : the earthquakes are represented with a "beach ball" if their focal mechanism are known and with a black circle if not. b-c) Reconstituted tide signal of Pointe-a-Pitre's tide gauge and real record of Limetree's tide gauge of November and December 2004 in figure c) and of November 20, 21 and 22 in figure d) with the time of the earthquake indicated in red 

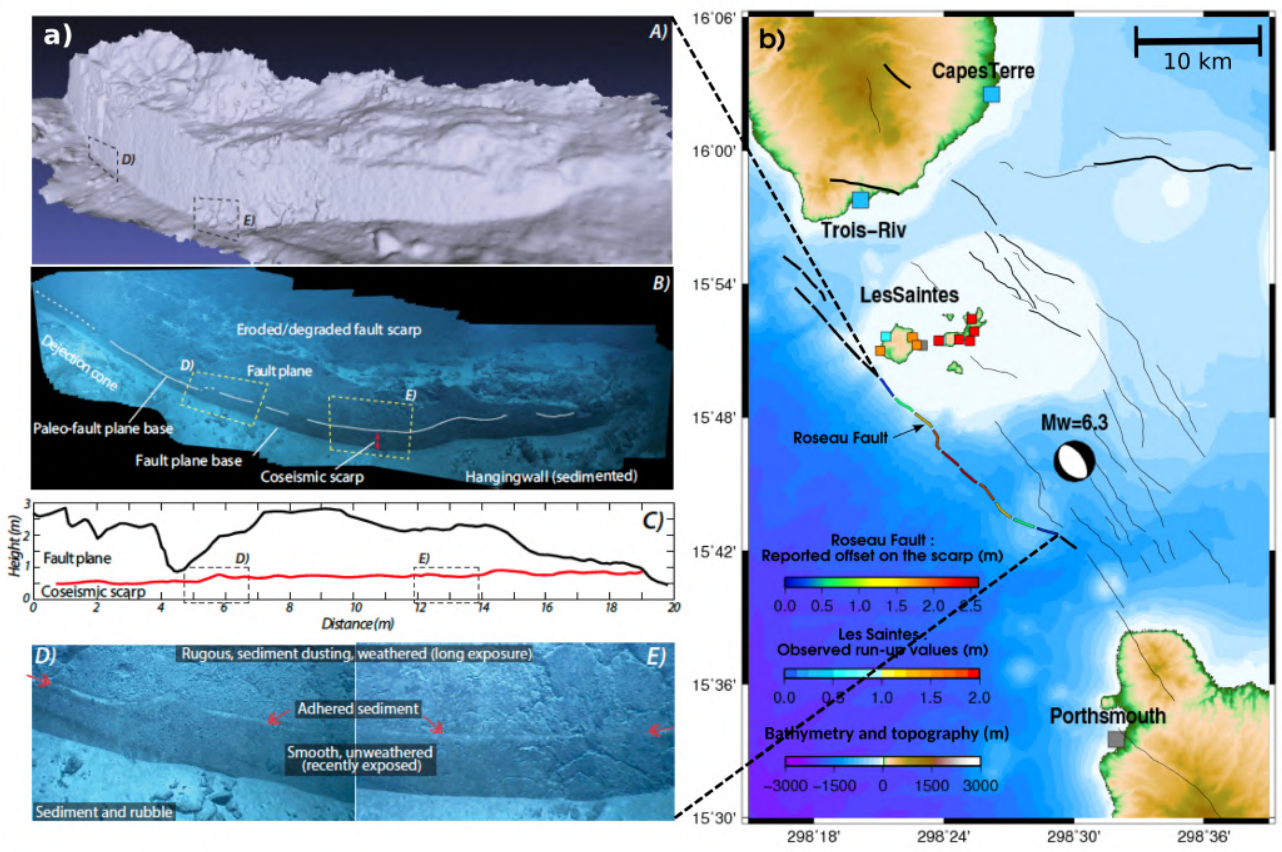

Fig. 2 a) Figure from Escartin et al. (2016). 3D terrain model derived from video imagery (A), corresponding videomosaic (B) showing the fault slip plane. Imagery and terrain model scan be used to document the coseismic fault displacement from the 2004 Les Saintes Earthquake (C). Differences in the nature and texture of the fault slip plane due to weathering and recent fault plane exposure are visible in video imagery (D and E). b) Map of the South of Guadeloupe and North of Dominica : the faults are represented by the thin black lines and the Roseau fault is represented with a segmented line whose color scale corresponds to a simplified, segmented displacement profile based on observations from the ODEMAR and SUBSAINTES cruises (Escartin et al., 2019). The colored squares correspond to the sites where observations of the tsunami have been reported.

\section{Tectonic and geological settings}

\subsection{Tectonic activity}

The volcanic arc of the Lesser Antilles results from the subduction of the Atlantic oceanic plate under the Caribbean plate which is monitored for its potential to generate large megathrust earthquakes. The subduction is not the only seismogenic zone of the region, as tectonic extension intra-arc also operates at shallower levels, with numerous intraplate faults identified. The only known and still debated megathrust earthquakes in the region are dated from 1839 and 1843 (Feuillet et al., 2011b) while seven Mw>5 intraplate earthquakes occurred during the last century: in $1935(\mathrm{Mw}=6.2$, near Montserrat), in 1950 and $1961(\mathrm{Mw}=6.0$ and $\mathrm{Mw}=5.5$ near Nevis and StKitts), in 1969 ( $\mathrm{Mw}=7.5$ near Barbados), in 1974 ( $\mathrm{Mw}=7.4$ between Barbuda and Antigua), in 1985 ( $\mathrm{Mw}=6.3$ near Redonda) and in 2004 ( $\mathrm{Mw}=6.3$ near Les Saintes). Among those events and among the historical catalog of the Lesser Antilles, only five generated a consequent tsunami (Shepherd and Lynch, 1992). The 
$\mathrm{Mw}=8.5$ earthquake of 1843 was followed by a $0.5-1.2 \mathrm{~m}$ tsunami in Guadeloupe and Antigua (Antigua Weekly Register, 1843; Sainte-Claire Deville, 1843). The $\mathrm{Mw}=6.7$ earthquake of 1867, which occurred in the Mona Passage generated up to $10 \mathrm{~m}$ waves in the Virgin Islands (Sainte-Claire Deville, 1867; Landers et al., 2002; Reid H.F. and Taber S., 1920). The deep $\mathrm{Mw}=7.5$ intraplate earthquake of 1969 was followed by a weak 10-40cm tsunami recorded in Barbados, Antigua, and Dominica (Shepherd, 2001; Stein et al., 1982). A $10 \mathrm{~cm}$ tsunami was recorded after the $\mathrm{Mw}=6.3$ Redonda earthquake of 1985 (Landers et al., 2002). In 2004, following the earthquake the population reported waves reaching more than $2 \mathrm{~m}$ in Les Saintes and $50 \mathrm{~cm}$ in the South of Guadeloupe (Zahibo et al., 2005; Le Friant et al., 2008). The Lesser Antilles innerarc shows faults that can be divided into two fault sets: one trench-perpendicular group of normal faults on the eastern edge of the arc that accommodates the trench parallel extension and a second set of en echelon normal faults between Les Saintes and Redonda that accommodates left-lateral transtension (Feuillet et al., 2000; 2002; 2011). The relative plate convergence of the Antilles subduction zone is known to be smaller than that of other subduction systems with a slip-rate of $19 \mathrm{~mm} / \mathrm{yr}$ (Demets et al., 2002). There is no precise measurement of the slip-rate along the inner-arc fault system but it is estimated to be around a few $\mathrm{mm} / \mathrm{yr}$ (Leclerc et al., 2016). With active faults up to $20-50 \mathrm{~km}$ long, this rate is sufficient to consider the occurrence of $\mathrm{M}>6$ shallow earthquakes as seriously as the occurrence of megathrust earthquakes along the subduction plate boundary. In the second set of faults, the en echelon normal fault system between Les Saintes and Redonda, the Roseau fault is the largest one with a length of $30 \mathrm{~km}$. Oriented NW-SE and dipping to the northeast (Fig. 2), this fault bounds the west side of Les Saintes islands and is linked to the group of faults forming a NW-SE graben.

\subsection{Morphology of Les Saintes}

Les Saintes is an archipelago of volcanic islands surrounded by a reef plateau formed on the volcanic edifices. high-resolution bathymetric mapping was done in the area during the BATHYSAINTES cruise (Deplus and Feuillet, 2010; Leclerc et al., 2014) and it shows the morphology and the structures of this reef plateau. The first kilometer around the islands corresponds to a shallow terrace of $25 \mathrm{~m}$ depth followed by a flat $50 \mathrm{~m}$ deep and $23 \mathrm{~km}$ wide plateau that extends more towards the northeast (Fig. 2) (Leclerc et al., 2016; Feuillet et al., 2011b; Leclerc et al., 2016; Leclerc and Feuillet, 2019). At the foot of the cliff (the border of the plateau), the depth jumps from $50 \mathrm{~m}$ to $250 \mathrm{~m}$ and then gradually increases reaching values of $500 \mathrm{~m}$ towards the east and values of $3000 \mathrm{~m}$ towards the west (Fig. 2). The bathymetry and the morphology of the seafloor have a major impact on the wave propagation and the simulation results show the importance of having high-resolution data on this archipelago. 
Table 1 Observations of the 2004 tsunami : Run-up heights extracted from the two field surveys (Zahibo et al., 2005; Le Friant et al., 2008) and associated wave heights calculated with a factor specific to each places

\begin{tabular}{|c|c|c|c|c|}
\hline Places $^{\text {a }}$ & Lon $\left(^{\circ}\right)$ & Lat $\left({ }^{\circ}\right)$ & Run-Up Height(m) & Wave Height (m) \\
\hline Marigot (TH) & -61.578 & 15.873 & 1.5 & 1.05 \\
\hline Grande-Anse (TH) & -61.576 & 15.864 & 2.0 & 1.6 \\
\hline Rodrigue (TH) & -61.579 & 15.857 & 2.0 & 1.8 \\
\hline Figuier (TH) & -61.588 & 15.858 & 1.6 & 1.2 \\
\hline Crawen (TH) & -61.603 & 15.857 & 0.8 & 0.64 \\
\hline Muriers (TB) & -61.616 & 15.854 & 0 & 1.5 \\
\hline Grande-Baie (TB) & -61.620 & 15.854 & 1.5 & 1.5 \\
\hline Grande-Anse (TB) & -61.623 & 15.859 & 2.0 & 0.4 \\
\hline Pajot (TB) & -61.644 & 15.860 & 0.5 & 0.9 \\
\hline Petite-Anse (TB) & -61.648 & 15.850 & 1.5 & 0.3 \\
\hline Trois-Riv & -61.664 & 15.963 & 0.3 & 0.3 \\
\hline Capesterre & -61.563 & 16.042 & 0.3 & \\
\hline
\end{tabular}

( $\mathrm{TB}=$ Terre de Bas, $\mathrm{TH}=$ Terre de Haut)

\section{Observations and data}

\subsection{Tsunami field surveys}

Two field surveys were conducted on the 27th of November 2004 and the 12 th of February 2005 and reported the damages generated by the earthquake and traces of the tsunami (Zahibo et al., 2005; Le Friant et al., 2008). The earthquake was strongly felt in the closest islands and caused one death and three injured persons in Trois-Rivières (Guadeloupe), one in Capesterre (Guadeloupe) and ten slightly injured persons in Petites-Anses (Les Saintes). Many buildings were damaged up to $65 \mathrm{~km}$ from the epicenter, the macroseismic intensity distribution in Guadeloupe for this event is presented in the BCSF report of 2005 (M. Cara, BCSF, 2005, hal01833992), it reaches intensities of VIII in Les Saintes and between IV and VIII in the main island of Guadeloupe. The observations of the tsunami are of two main types : (1) eyewitness records giving an estimation of the arrival time and the height of the waves; (2) seaweed, fishes and various objects found on the beaches or cliffs which provide rough estimations of the run-up height and distance values. The values, drawn from the field surveys reports (Zahibo et al., 2005; Le Friant et al., 2008), are listed in Tab. 1. The biggest run-up height is the $2 \mathrm{~m}$ reported on Grande-Anse beach in Terre-De-Haut (Les Saintes), the biggest run-up distance is $42 \mathrm{~m}$ reported in Anse Rodrigue and the furthest observation was made in Capesterre $30 \mathrm{~km}$ from the epicenter. The run-up height, which is the maximum inundation point above sea level of a wave incident to the coast-line, is generally higher than the height of the wave before reaching the land. It is a local characteristic that depends on the coastal geometry, topography, and nature of the land, and that can be modeled by Calypso (details in section 4).

\subsection{Tide and gauges}

Unfortunately in 2004, no tide gauge was operational in Guadeloupe or Dominica, so no instrumental record of the tsunami is available. Pointe-À-Pitre tide gauge was 
installed in 1991 and recorded the tide mean hour value of those last thirty years with some gaps in the data due to non-operating periods. A MatLab tidal analysis toolbox that uses harmonic analysis to estimate tidal constituents (Pawlowicz et al., 2002) was used to restore the missing 2004-2005 period of Pointe-À-Pitre tide record (Fig. 1) based on the available data. On the 21st of November 2004, the closest available tide gauge was located $400 \mathrm{~km}$ away in St.Croix LimeTree Bay, and it recorded a tide evolution similar to the reconstituted one in Pointe-À-Pitre presented Fig. 1. At the time of the tsunami (8h00-UTC), the sea-level was close to the mean sea level of the area and no exceptional tide occurred this day that should be considered in the simulation.

\subsection{Earthquake slip models}

The initial fault parameters given by the USGS Moment Tensor Solution and the Harvard CMT inversion show that the main shock occurred at around 10km depth within Les Saintes fault system (Bazin et al., 2010). Its hypocentral location is compatible with the mean dip of $50^{\circ}$ of the Roseau fault, the only candidate with a plane model in agreement with the focal mechanism. More complex source models have been determined from the inversion of teleseismic data (Salichon et al., 2009) and the joint inversion of teleseismic data and strong motion records (Feuillet et al., 2011a). The latter one consists of a single fault segment $31.5 \mathrm{~km}$ long and $19.5 \mathrm{~km}$ wide, subdivided into 273 sub-faults measuring $1.5 \mathrm{~km}$ along strike and dip (Tab. 2 and Fig. 5p. It is characterized by two main slip patches, located at around $10 \mathrm{~km}$ depth to the SE and NW of the hypocenter. It suggests that the largest slip occurred at depth with a maximum of $1.8 \mathrm{~m}$ in the SE slip zone. The slip propagated toward the surface with moderate amplitude $(<1 \mathrm{~m})$ implying a coseismic offset of $0.3 \mathrm{~m}$ to $0.6 \mathrm{~m}$ of the seafloor along the Roseau fault.

\subsection{Seafloor constraints on coseismic displacement}

In 2013 (ODEMAR cruise, doi:10.17600/13030070) and 2017 (SUBSAINTES cruise, doi:10.17600/17001000) the Roseau Fault was surveyed using remotely operated and autonomous underwater vehicles. The coseismic rupture was identified at the base of the Roseau Fault scarp, extending $>15 \mathrm{~km}$ laterally. Preliminary displacement profiles based on 3D terrain models derived from video imagery (Istenic et al, 2019; 2020), reveal a coseismic displacement profile that tapers from the ends of the rupture to its center, with a maximum observed coseismic vertical displacement of 2,5m (Escartin et al., 2019). These displacements are significantly larger than vertical displacements of $1 \mathrm{~m}$ predicted from earthquake slip models (Feuillet et al., 2011a; Escartin et al., 2016). Furthermore, there is inherent uncertainty regarding the possible contribution of after-shock and post-seismic slip to the observed vertical rupture displacement. In this case, the reactivation of the Roseau fault with an identical rake would be associated with a lowered estimation of the coseismic slip, and on contrary, the reactivation of the Roseau fault with an opposite rake would be associated with a highered estimation of the coseismic slip. 


\section{Methodology}

4.1 Calypso : Code and equations

Calypso code Calypso is a parallelized numerical code developed by Heinrich et al. (1998) and Hebert et al. (2001) which computes the propagation of tsunami waves generated by a seismic source. It has been applied to numerous worldwide tsunamis and has proven its efficiency, especially in the Pacific through the simulation of waves triggered by historical and great earthquakes of the last decades where ample data is available to validate the simulations (Hébert et al., 2007; Hébert et al., 2009; Reymond et al., 2012; Schindelé et al., 2015; Poupardin et al., 2018). The simulation is composed of three steps: the initiation of the wave, the propagation, and the run-up at the coast.

Initiation : Okada model and Transfer function The initiation is the seafloor deformation generated by the rupture of the fault and modeled using the Okada (Okada et al., 1985) formalism. It assumes an elastic, isotropic, and homogeneous medium in which is buried a rectangular fault ruptures with a uniform slip. It gives the ground displacement as a function of geometric parameters (dip, strike and slip angles, fault length and width, depth and slip dislocation) and of the parameters of the surrounding rock. Compared with the tsunami velocity $(0.2 \mathrm{~km} / \mathrm{s})$, the rupture velocity (about $3 \mathrm{~km} / \mathrm{s}$ ) is large, so the ground displacements over the faulting regions are assumed to be instantaneous for the modeling of the waves. The seawater is generally considered as a homogeneous, incompressible and non-viscous fluid. In the 2004 earthquake case, the bottom deformation due to the surface rupture is too sharp and a transfer function was implemented in the code to compute the initial surface deformation. This function is based on the formula of Kajiura (1963) which calculates the initial surface elevation generated by a sea bottom deformation in an ocean of constant depth. The copy of the bottom deformation is valid only for horizontal characteristic lengths that are assumed to be large compared to the water depth. A transfer function has to be used for short horizontal deformations such as produced by seismic faults that rupture the ground surface. The main role of the transfer function is to eliminate the short non-physical water waves generated by discontinuities of the ground deformation. A short description of this transfer function is given in the following paragraph, where equations are written in Cartesian coordinates for simplicity. (x,y) denote the grid horizontal coordinates and $(\Delta x, \Delta y)$ denote the associated grid steps. The calculation of the transfer function is based on the linear potential theory (Kajiura, 1963). Assuming a constant water depth d and an instantaneous vertical bottom deformation $\Delta z$ at $\left(\mathrm{x}^{\prime}, \mathrm{y}^{\prime}\right)$ the water surface displacement $\Delta \eta$ at $(\mathrm{x}, \mathrm{y})$ writes as:

$$
\begin{gathered}
\Delta \eta=G(r) \Delta x \Delta y \frac{\alpha \Delta z\left(x^{\prime}, y^{\prime}\right)}{2 \pi d^{2}} \\
r=\frac{\sqrt{\left(x-x^{\prime}\right)^{2}+\left(y-y^{\prime}\right)^{2}}}{d} \\
G(r)=E \int_{0}^{\infty} \frac{k J_{0}(k r) d k}{\cosh k}
\end{gathered}
$$


where $\mathrm{G}$ is the Green function and $\alpha=1$ for uniform depths. For non-uniform water depths, the above formula is not valid anymore but is still a good approximation according to Glimsdal et al. (2013), provided the depth variations $\Delta z$ are small compared to the water depth. In this case, the formula requires the calculation of $\alpha$ in such a way that the displaced volume at the sea surface is equal to the displaced volume of the ocean bottom. For a given bottom deformation $\Delta z$, the volume displaced at the sea bottom is $(\Delta x \Delta y \Delta z)$ and $\alpha$ is chosen as to preserve the displaced volume of water over the whole grid:

$$
\sum_{x, y} \Delta \eta(x, y) \Delta x \Delta y=\Delta x \Delta y \Delta z
$$

Propagation : Shallow Water equations This code solves nonlinear shallow water equations, written in spherical coordinates. If the tsunami waves present a wavelength much larger than water depth, then the horizontal length scale is much greater than the vertical length scale and the conservation of mass implies that the vertical velocity of the fluid is small. The vertical velocity field can be neglected, and the wave velocity is approximated by the relation:

$$
c=\sqrt{g h}
$$

Under this condition, the propagation can be calculated by solving the shallow water equations that generalize the 1D Saint-Venant equations derived from depthintegrated Navier-Stokes equations. The continuity equation expresses conservation of water volume for this incompressible homogeneous fluid. The momentum equation expresses the balance between forces and momentum change rates. They are developed into the $2 \mathrm{D}$ equations, which are solved in spherical coordinates $(\varphi, \theta)$ where $\varphi$ and $\theta$ are the longitude and the latitude:

$$
\begin{gathered}
\frac{\partial h}{\partial t}+\frac{1}{\cos \theta}\left(\frac{\partial u h}{\partial \varphi}+\frac{\partial \cos \theta v h}{\partial \theta}\right)=0 \\
\frac{\partial u}{\partial t}-f v+\frac{1}{\cos \theta}\left(u \frac{\partial u}{\partial \varphi}+\cos \theta v \frac{\partial u}{\partial \theta}-\sin \theta u v\right)=-g \frac{1 \partial \eta}{\cos \theta \partial \varphi}+F_{\varphi} \\
\frac{\partial v}{\partial t}+f u+\frac{1}{\cos \theta}\left(u \frac{\partial v}{\partial \varphi}+\cos \theta v \frac{\partial v}{\partial \theta}-\sin \theta u^{2}\right)=-g \frac{1 \partial \eta}{\partial \theta}+F_{\theta} \\
F_{\varphi}=g n^{2} u \frac{\sqrt{(u)^{2}+(v)^{2}}}{(h+d)^{4 / 3}} \\
F_{\theta}=g n^{2} v \frac{\sqrt{(u)^{2}+(v)^{2}}}{(h+d)^{4 / 3}}
\end{gathered}
$$

where $d$ is the water depth, $\eta$ is the surface elevation and $h=\eta+d,(u, v)$ are the depth-averaged velocities along $(\varphi, \theta), f$ is the Coriolis parameter and $\left(F_{\theta}, F_{\varphi}\right)$ the bottom friction force based on the Manning's formulation and $n$ the roughness coefficient in s.m -3. This latter force is neglected in our simulation since one-dimensional tests show that its contribution is minor in terms of wave arrival times. 
Numerical methods This code solves nonlinear shallow water equations, written in spherical coordinates. The nonlinear long-wave equations are solved by means of a staggered-grid finite difference method. Nonlinear terms in the model are approximated with upwind finite differences, and linear terms are approximated by centered finite differences. The temporal scheme uses an iterative procedure and is based on a second-order Strong Stability-Preserving Runge-Kutta method. To deal with shoaling and resonance effects of the tsunami waves, detailed bathymetric grids are used for the precise modeling of the coastline response in bays and harbors. To this end, we calculated wave propagation on successive levels of nested grids of increasing resolution close to the shore, built using available bathymetric and topographic data. Open free boundary conditions are prescribed to the boundaries of the mother grid covering the studied area, and wave heights along the boundaries of a fine grid are spatially interpolated at each time step from the value computed in the coarse grid containing the fine grid. The code can also solve the Boussinesq equations that take into account the frequency dispersion. We performed some simulations with these Boussinesq equations and the results were quite identical to the results with Shallow water equations. The main reason is probably that the dispersion effects mostly appear in the far-field and for deepwater areas. We focused here on the near-field effects of the tsunami and Les Saintes area does not present so important water depths.

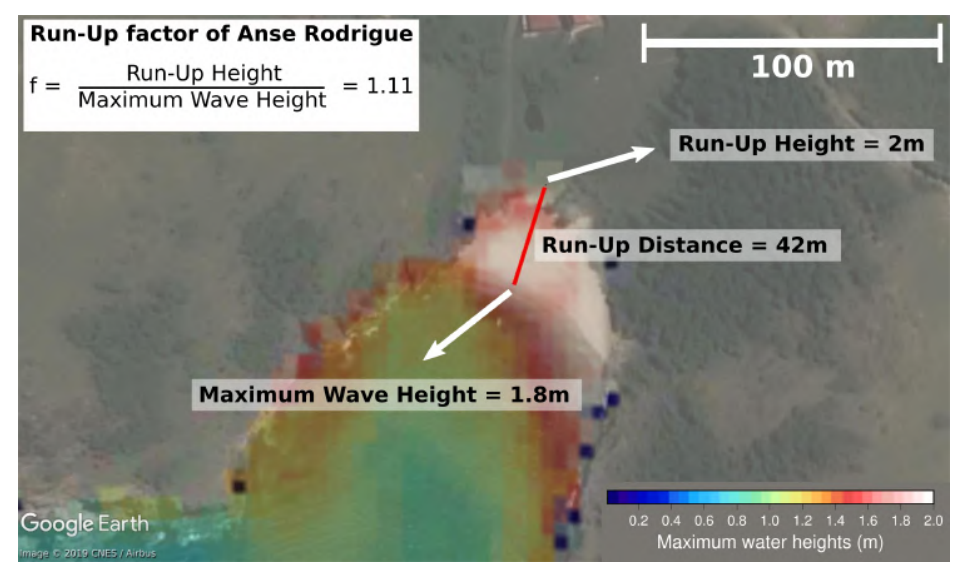

Fig. 3 Illustration of the run-up factor calculation done for Anse Rodrigue based on the runup height, run-up distance and maximum wave height. The map and values are extracted from the model 4 simulation.

Run-Up The method takes into account the inundation of the coastal areas and allows us to compute run-up values thanks to the topography provided within the first emerged tens of meters of the finer grids. Numerically, this is handled by an extrapolation of the results from dry to wet nodes at the dynamic shoreline. Some of the simulations performed for this study, result in important run-up values but some others result with small water heights and no run-up values. To compare similar objects for all the simulations, it was decided not to use the run-up height but the maximum wave height at the coastline and since most of the observations reported were run-up values, it was necessary to estimate their associated wave height. To 


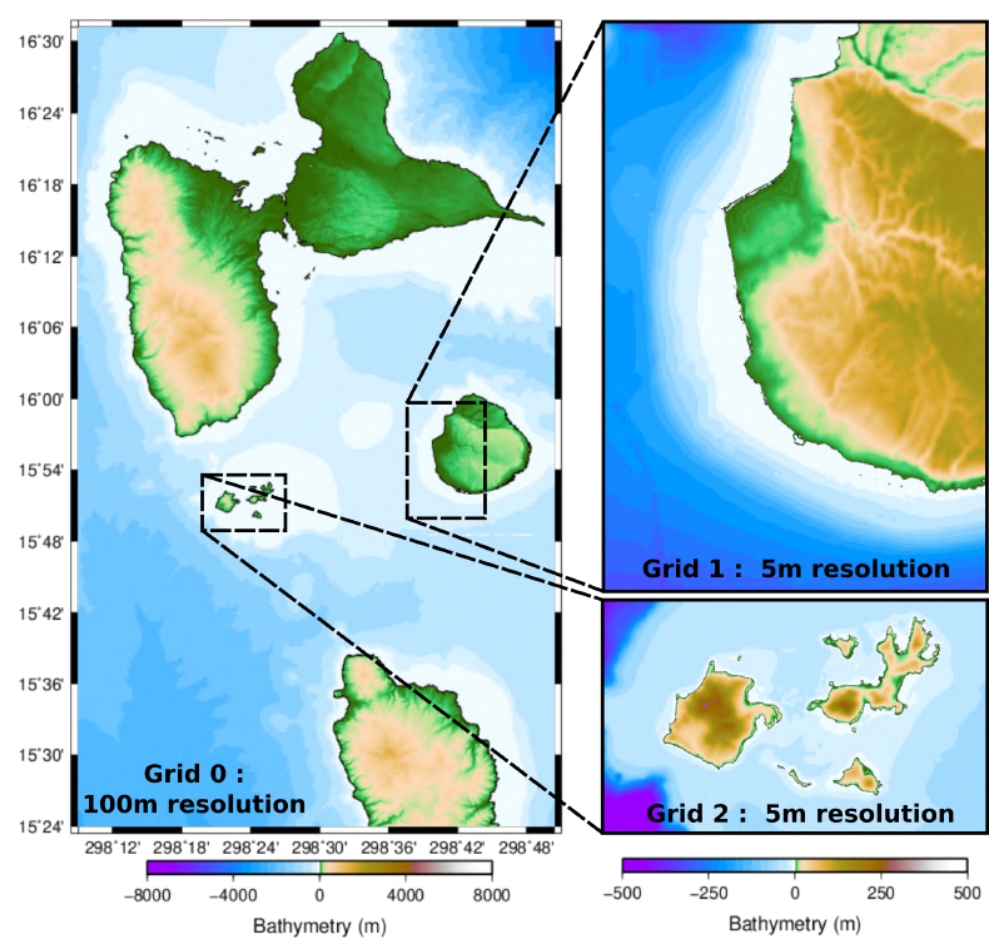

Fig. 4 Set of nested grids used for the simulations. Grid 0 is the mother grid of $100 \mathrm{~m}$ resolution (SHOM,2015. MNT Bathymétrique de façade Atlantique (Projet Homonim). http: //dx.doi.org/10.17183/MNT_ATL100m_HOMONIM_WGS84), grid 1 is a daugther grid of 5m resolution centered on the western coast of Marie Galante and grid 2 is a daugther grid of $5 \mathrm{~m}$ resolution centered on Les Saintes (SHOM, LITTO3D Guadeloupe 2016. https://diffusion. shom.fr/media/wysiwyg/pdf/Specifications-techniques-Litto3D_v1_0-Doc_v1_5.pdf).

obtain this "run-up factor" between the maximum wave height and its associated run-up height at each of the places, we used the results of the maximizing scenario simulation that produces important run-up in Les Saintes. The run-up height and the associated wave height at the coast-line were extracted from each of the 12 studied places, and we were able to compute their "run-up factor" $f=($ Run-Up/Hmax $)$, varying from 1 to 2. The height values for Anse Rodrigue are illustrated in figure Fig. 3. The wave height presented in the fifth column of the Tab. 1 corresponds to the observed run-up height multiplied by the associated run-up factor. All the graphics and figures presented in this paper are based on those maximum wave heights and not on the run-up heights. This relation between run-up of wave heigh is complex because of the non-linear effects of the bathymetry, the nature of the floor, the vegetation or buildings. The linear approximation that we use enables rapid comparison of the results, but it would be interesting to develop some formulas taking into account more complex effects. The code also includes a roughness coefficient that expresses the friction of the water on the floor based on the Manning's formula (Eq.9 and Eq.10) and can be chosen depending on the nature of the floor. We performed some 
simulations with different Manning values but this factor does not have a strong effect on the results due to the small run-up distances at stake so it was decided not to go further into this question.

4.2 Modeling strategy

Table 2 Sources parameters of the models

\begin{tabular}{|c|c|c|c|c|c|c|}
\hline Models & $M w$ & Length ${ }^{*}$ Width $\left(\mathrm{km}^{2}\right)$ & Strike $\left({ }^{\circ}\right)$ & $\operatorname{Dip}\left({ }^{\circ}\right)$ & $\operatorname{Rake}\left({ }^{\circ}\right)$ & $\operatorname{Slip}(m)$ \\
\hline Model 1: Seismic inversion model & 6.3 & $20 * 15$ & 325 & 55 & $-80<\theta<-110$ & $0<S<2$ \\
\hline Model $2: 1.5 \mathrm{~m}$ surface slip model & 6.3 & $15 * 15$ & 325 & 55 & $-80<\theta<-110$ & $0<S<2$ \\
\hline Model $3: 2.5 \mathrm{~m}$ surface slip model & 6.4 & $15 * 15$ & 325 & 55 & $-80<\theta<-110$ & $0<S<2.5$ \\
\hline Model $4: 3.5 \mathrm{~m}$ surface slip model & 6.5 & $15 * 15$ & 325 & 55 & $-80<\theta<-110$ & $0<S<3.5$ \\
\hline Model 3 NT : No Transfer Function model & 6.4 & $15 * 15$ & 325 & 55 & $-80<\theta<-110$ & $0<S<2$ \\
\hline Model $3 \mathrm{H}$ : Homogeneous model & 6.4 & $15 * 15$ & 325 & 55 & -88 & $0<S<2$ \\
\hline
\end{tabular}
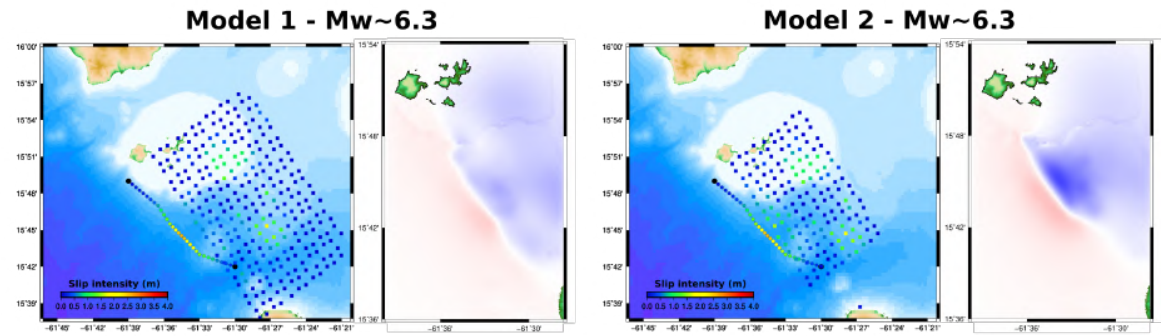

Model 3 - Mw 6.4

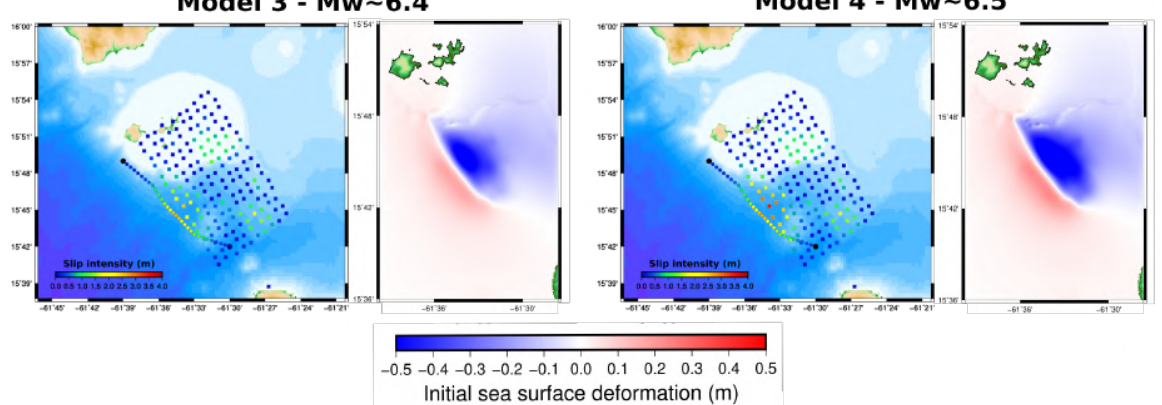

Fig. 5 Fault models and corresponding initial sea surface deformation map of the models 1, 2, 3 and 4. For each model, the left figure is a grid of the fault model with the color scale associated to the slip magnitude associated to each segment (model 1 has 273 segments, models 2, 3 and 4 have 178 segments), the line of colored circles represents the Roseau fault scarp with the color scale associated to the offset observed during the ODEMAR and Subsaintes campaign (Escartin et al., 2017). The right figure is a map of the initial sea surface deformation generated by the associated fault model. 
The tsunami simulations were performed using nested bathymetric grids of $100 \mathrm{~m}$ and $5 \mathrm{~m}$ resolution (Fig. 4). The source models were built from the complex seismic rupture suggested by (Feuillet et al., 2011a), and including information newly provided by the data from the 2017 fault survey (Escartin et al., 2019). This heterogeneous rupture is modeled by a set of rectangular segments with independent values of size, depth, shear modulus, slip intensity, and orientation. The modeling results that can be found in our earlier published work (Cordrie et al. 2019) were obtained with coarser grids and were focused on the impact of the slip intensity. Those models were improved and they enable a better understanding of the impact of the slip intensity and the impact of the rupture heterogeneities and the energy transfer from the fault to the sea surface.

Choice of the parameters The results of inversions and the good knowledge of the Roseau fault system give good constrains for the location, orientation, and size of the rupture. The values of strike and dip are fixed to $325^{\circ}$ and $55^{\circ}$ respectively, while the rake varies from $-80^{\circ}$ to $-110^{\circ}$ depending the segments with a strong normal component and a small strike-slip component. The size of the fault (length and width) and the amount of slip impact the tsunami wave amplitude. We estimate those parameters using the empirical equation of Wells and Coppersmith (Wells and Coppersmith, 1994). They are linked to the seismic moment (Eq.11) and directly connected to the magnitude (Eq.12):

$$
\begin{gathered}
M_{0}=\mu A d \\
M_{w}=\frac{2}{3}\left[\log _{10}\left(M_{0}\right)-16.1\right]
\end{gathered}
$$

where $M_{0}$ is the seismic moment, $\mu$ is the shear modulus of the medium crossed by the rupture (in $P a$ ),$A=L * W$ is the area of the rupture $\left(m^{2}\right), d$ is the average slip of the rupture and $M_{w}$ is the magnitude. The magnitude is estimated at 6.3 , the shear modulus $\mu$ is fixed at $30 \mathrm{GPa}$ in the first $5 \mathrm{~km}, 35 \mathrm{GPa}$ from $5 \mathrm{~km}$ to $20 \mathrm{~km}$ depth, $40 \mathrm{GPa}$ from $20 \mathrm{~km}$ to $40 \mathrm{~km}$ depth, those values are calculated using the results from (Paulatto et al., 2017). The rupture is concentrated on a $15 \mathrm{~km}$ long and $15 \mathrm{~km}$ large plane, reaching $10 \mathrm{~km}$ at depth. The distribution of the slip is the most uncertain parameter, two high slip areas appear in the results of inversion and an important surface displacement was revealed during the ODEMAR and Subsaintes campaign (Escartin et al., 2017). For each segment, the shear modulus is determined by its depth and the slip intensity is chosen considering the magnitude of the event and the size of the fault (defined by the sum of all the segments), respecting $\operatorname{Eq}(9)$.

Faults models The four tested source models are presented in Tab. 2 and Fig. 5. The model 1 corresponds to the complex fault model with 273 segments of Feuillet et al. (2011) with a magnitude of 6.3 .

The model 2 was built increasing the slip on the segments at the surface with a distribution inferred from seafloor observations (Escartin et al., 2019), while keeping an earthquake magnitude of $\mathrm{Mw}=6.3$ by decreasing the slip intensity on the deeper segments of the fault.

The model 3 is a combination of the model 2 segments and a set of shallower segments corresponding to the maximum vertical displacement of $2.5 \mathrm{~m}$ observed at the center of the rupture (Escartin et al., 2019). The model 3 is similar to the model 2 but its final magnitude is 6.4 , it is higher than 6.3 but it is reasonable to make 
the assumption that the near-surface rupture may reflect shallow processes and that the associated displacement may not contribute to the magnitude calculation (e.g., no effective confining pressure and therefore no significant frictional energy). The underestimation of an earthquake magnitude considering its surface rupture is has been observed and studied for other events like the Mentawai earthquake in 2011 (Newman et al., 2011) or an Ecuadorian Andes earthquake in 2010 (Champenois et al., 2017).

The model 4 is identical to the model 3 but with a maximum vertical fault displacement of $3.5 \mathrm{~m}, 1 \mathrm{~m}$ higher than that observed at the seafloor giving a magnitude of 6.5. As seafloor observations are limited to a limited area along the base of the fault scarp, off-fault coseismic deformation, which may contribute to vertical displacements of the seafloor, cannot be constrained nor quantified. This model was added because it appeared that the models 1,2 and 3 produce globally very small run-up and it was needed to increase the slip beyond the offset value in order to match the observations.

Two additional simulations based on model 3 parameters were performed in order to study the impact of the transfer function and the source heterogeneity presented in the discussion (Fig. 12 and Fig. 13 .

The model 3NT (No Transfer) presented in Fig. 12 is identical to model 3 but the simulation was performed without the use of the transfer function, meaning that the initial sea surface deformation is the Okada's ground deformation transmitted to the sea surface.

The model 3H (Homogeneous) presented in Fig. 13 is the homogeneous version of the model 3. The fault plane is defined by only one segment which has the size of the fault model $3\left(18 \mathrm{~km}^{*} 18 \mathrm{~km}\right)$ and whose $0.4 \mathrm{~m}$ uniform slip was calculated in order to match the magnitude 6.4 of the model 3. The depth and fault angles (depth $=7.5 \mathrm{~km}$, strike $=325^{\circ}$, dip $=55^{\circ}$, rake $=-88^{\circ}$ ) were chosen based on model 3 geometry and parameters.

\section{Results of simulation}

\subsection{General analysis}

The simulations were performed for 45 minutes only but the tsunami reaches most of the neighboring coasts between 10 and 30 minutes. In all the simulations, the tsunami wave globally propagates in a similar way (Fig. 6): it firstly propagates towards the North-East, it gains amplitude when reaching the Saintes carbonate platform, reaches the South-East coasts of Les Saintes, then it bypasses them by the west and progressively from East to West and reaches the Northern coasts of Les Saintes and Guadeloupe. This asymmetric tsunami path around the islands produces late arrivals of the strongest wave at the northern coast of Les Saintes, a phenomenon that can be observed on the synthetic tide gauge of Grande Anse in Terre de Bas (Fig. 9 ) where the first arrivals are detected 10 minutes after the earthquake with waves of $20 \mathrm{~cm}$ but the highest wave arrives 25 minutes after the earthquake so 15 minutes after the first arrival with a height of $80 \mathrm{~cm}$. The first tsunami arrivals are not always the strongest and most dangerous ones and an unexpected late tsunami wave could create great damages to an unaware population. This phenomenon is due to the morphology of the 


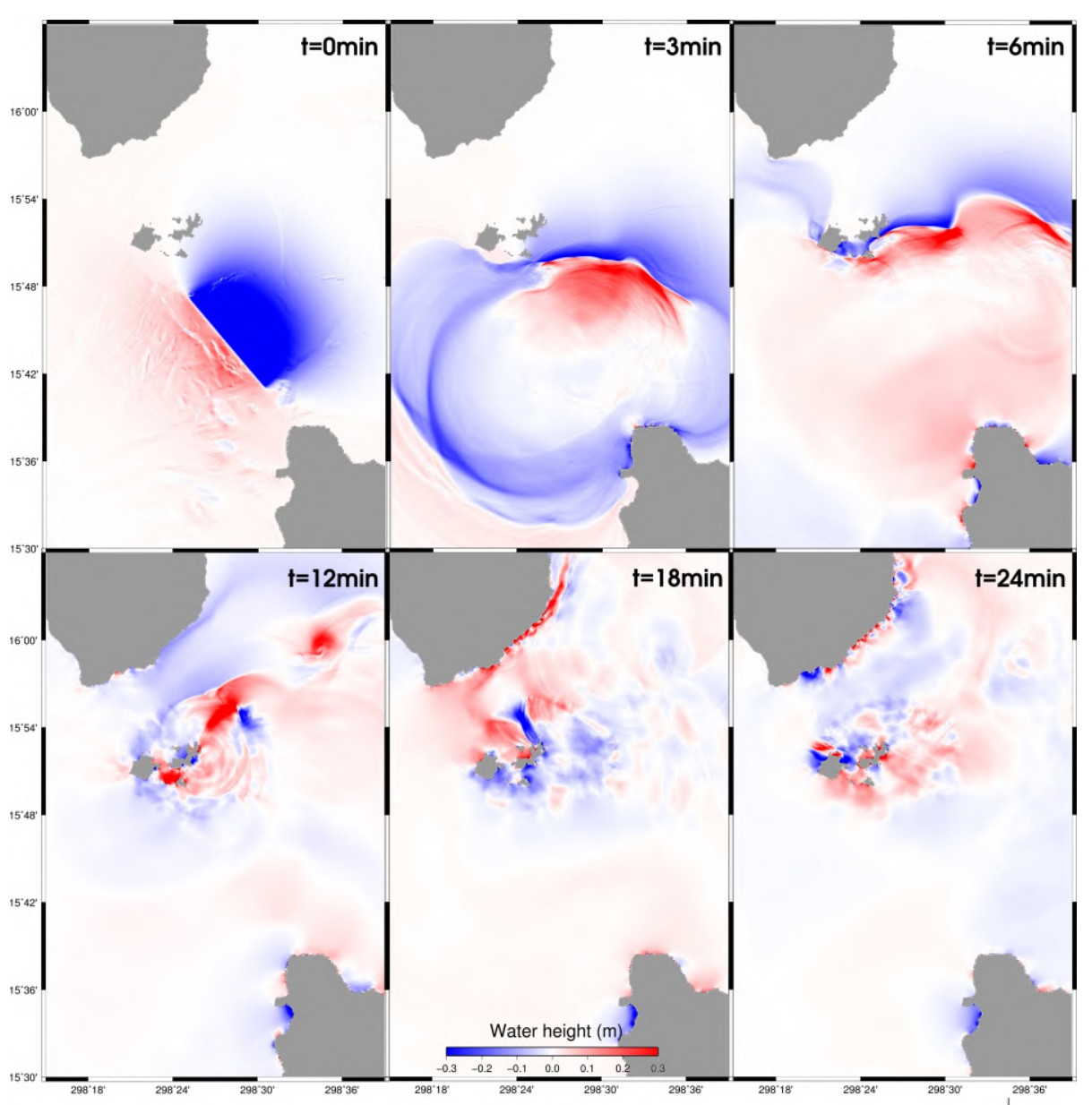

Fig. 6 Maps of the sea surface height simulated from the model 3H, at 0, 3, 6, 12, 18 and 24 minutes after the earthquake.

platform and can only be modeled with high-resolution bathymetry and fairly long simulations. Previous studies underestimated tsunami height at this same location (Le Friant et al., 2008) because of their too short simulation time and the lowest quality of the bathymetric grids available at the time.

Maps of the water height after 45 minutes of tsunami propagation show many local effects of wave amplification along the coasts due to bathymetric changes as it is shown in Fig. 6, Fig. 7 and Fig. 8 The carbonate platform of Les Saintes corresponds to a sudden decrease of the water depth which causes this wave amplification observed on the maps. The wave is also amplified towards Marie-Galante island while there are no specific bathymetric features along the way. There might be a concentration of the energy in this direction which is perpendicular to the fault line. The east of Marie Galante, the south of Guadeloupe and the north of Dominica are affected by centimetric waves but not the rest of the arc. The simulated tsunami models have a local impact that is coherent with all the witnesses. 

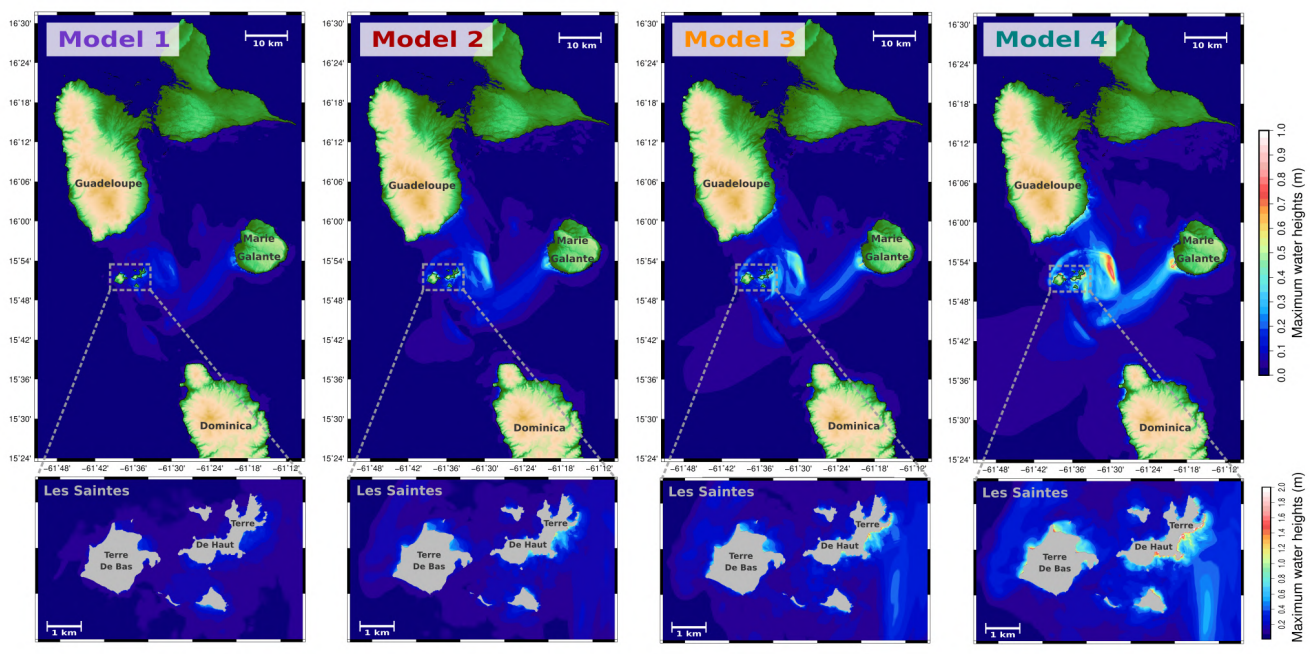

Fig. 7 Top figures : Maps of the maximum water heights (hmax) obtained after 45 minutes of tsunami propagation for the model 1,2,3 and 4. Bottom figures: Maps of the maximum water heights (hmax) obtained on Les Saintes islands with an increased colorbar.
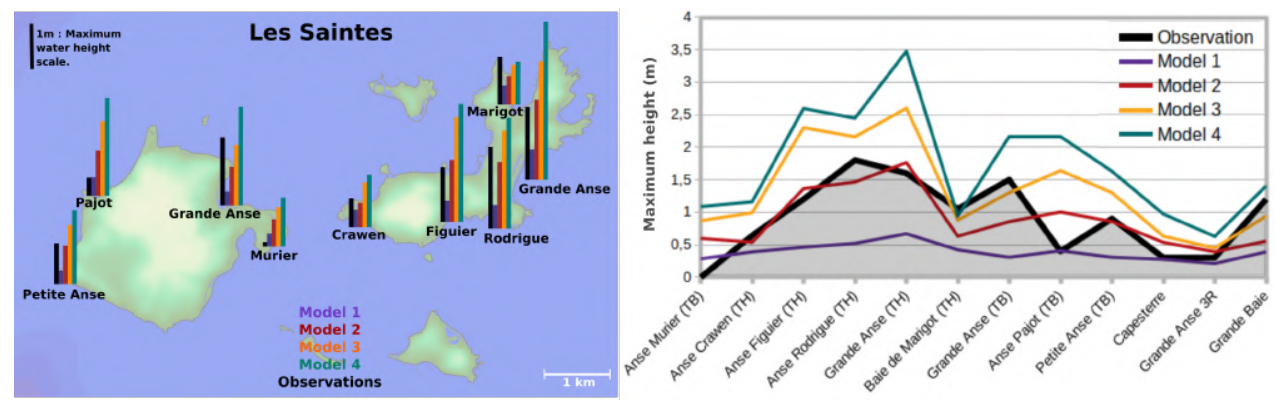

Fig. 8 Map of Les Saintes islands with the values of maximum water heights (Hmax) extracted from 9 coastal sites where tsunami traces have been reported, the 5 colored bars correspond to the Hmax value from the observed data and the 4 simulations: model 1 in purple, model 2 in red, model 3 in orange, model 4 in green and the observations in black. Those values are presented in the associated graphic with 3 additional places: Capesterre (Guadeloupe), TroisRiviere (Guadeloupe), and Grande Baie (Les Saintes). TH: Terre de Haut (eastern island of Les Saintes) and TB: Terre de Bas (western island of Les Saintes)

The synthetic signals of the wave extracted at 4 locations in Les Saintes, at TroisRivières (Guadeloupe) and Portsmouth (Dominica) are presented in Fig. 9 The four simulations produce similar wave arrival times (Fig. 9) of 5 to 15 minutes which are similar in magnitude to those reported by the inhabitants in Anse des Muriers (first arrival observed 3 minutes after the earthquake) and in Baie de Marigot (observation 5 minutes after the earthquake). Considering the uncertainty of those testimonies (due to the context and the weak intensity of the event), time arrival mismatches of 

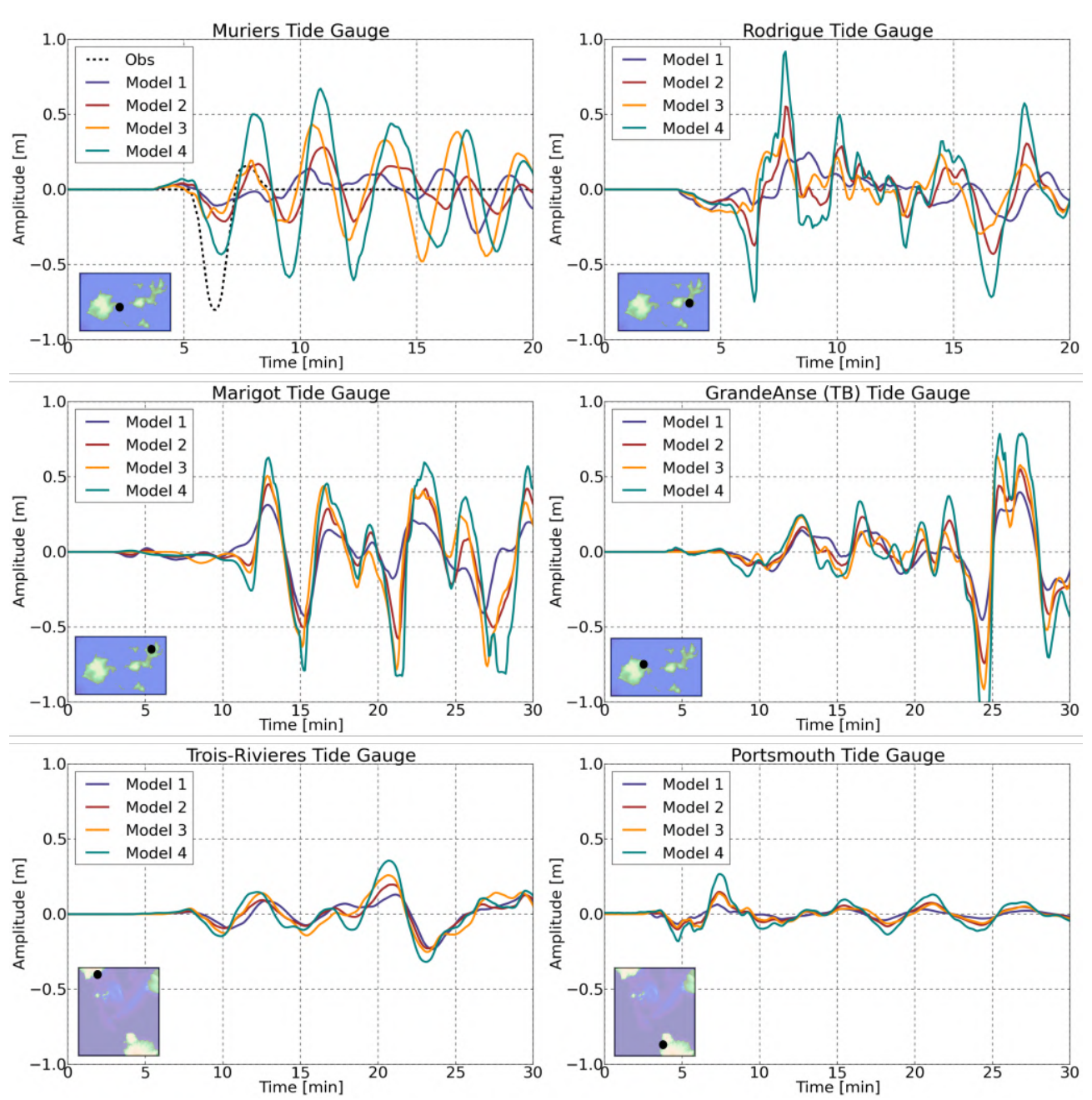

Fig. 9 Synthetic tide gauges of the 4 models calculated at 4 places around Les Saintes islands (Anse Muriers, Anse Rodrigue, Baie de Marigot and Grande Anse), at Trois-Rivières (Guadeloupe) and at Portsmouth (Dominica) with the location indicated in the small maps associated to each graphic.

few minutes are not determinant. The synthetic signals enhance, for the 4 models, the short period of the tsunami wave. Generally, the tsunami wave period typically ranges from 10-60 minutes (ref) while the period is around 2-3 minutes in Les Saintes and 5 minutes further away (Trois-Rivières and Portsmouth). Even if it is quite small, this period is coherent with witnesses, a ship captain reported that 3 minutes after the earthquake, the sea receded $5 \mathrm{~m}$ (and dropped $80 \mathrm{~cm}$ ) and rose back to its still level, over perhaps 1 minute (LeFriant et al, 2008). We used this observation made in Anse Muriers to create a reconstitution of the signal plotted in dashed black in the first graphic of Fig. 9. Due to the shallowness of the rupture, the initial sea surface deformation for all the models is mainly concentrated (Fig. 5) on a small patch of around $10 \mathrm{~km}$ width that initiates a wave with $\lambda=10 \mathrm{~km}$ of wavelength. 
The water depth above the fault is $h=1 \mathrm{~km}$ so the wave velocity is approximately (using Eq.5) $c=100 \mathrm{~m} / \mathrm{s}$, and the period of a $10 \mathrm{~km}$ long wave propagating at $100 \mathrm{~m} / \mathrm{s}$ is $T=100 \mathrm{~s}=1.6 \mathrm{~min}$ which is coherent with the results.

\subsection{Regional model's comparison}

The values of maximum heights presented in Fig. 7 and Fig. 8 increase almost proportionally to the surface slip intensity of the models. Indeed in Grande Anse for example (graphic in Fig. 8), the Hmax value of $0.5 \mathrm{~m}$ obtained with the model $1(0.2 \mathrm{~m}$ surface slip) jumps to $3.5 \mathrm{~m}$ with the model 4 (3.5m surface slip). However, the amplification of the signal is not homogeneous, in some places like Anse Rodrigue, Anse Figuier, Grande Anse (TH) and Grande Anse (TH) the signal is strongly amplified while the impact is not so important in Baie de Marigot or Trois-Rivières (Fig. 8 and Fig. 9). The differences in all those places mainly come from their position and distance to the source as well as their geometry and topography. The distribution of the maximum water heights obtained from the field surveys gives the minimum values of water height reached by the tsunami knowing that the tsunami might have reached even greater heights that were not observed or reported. To consider a model as a potential source of the 2004 earthquake, the resulting water heights should be at least equivalent and even greater than the observed one. Models 1 and 2 give back water heights globally smaller than the observations (curves in the gray area of the graphic in Fig. 8 while models 3 and 4 give back great enough heights. The observed water heights were mainly estimated from deposited debris or traces that testify of a minimum level of water but where the waves were probably higher than that to be capable of transporting debris and leaving marks up to those sites. The tsunami produced by model 2 reaches the observed height but could not transport debris up to those heights while model 3 and 4 tsunamis that exceed the observed heights are better candidates for depositing debris at the reported sites. Considering those regional results, the surface slip needed to fit the observation seems to be at least $2 \mathrm{~m}$ (model 3) or even bigger (model 4) meaning that the simulations are coherent with the recent measures of the Roseau fault coseismic slip.

\subsection{Les Saintes model's comparison}

Results of simulations on Les Saintes $5 \mathrm{~m}$ resolution grids are helpful in the analysis of the fault models because they enable a direct comparison of the run-up distance generated by the models with run-up traces reported in the field surveys (Fig. 10 . Three important run-up occurred in Les Saintes after the earthquake, one in Grande Anse (TB) where the water reached a restaurant $22 \mathrm{~m}$ from the shore (first column in Fig. 10), one in Baie de Marigot where the water reached a house located $15 \mathrm{~m}$ from the shore (second column in Fig. 10) and one in Anse Rodrigue where a charred tree was loaded $42 \mathrm{~m}$ inland from the shore (third column in Fig. 10. As expected models 1 generates almost no run-up at those places, models 2 and 3 both generate small run-up but not as important as the observed one, and interestingly in Anse Rodrigue model 2 run-up is greater than model 3 showing the complexity of the processes. Finally, only the model 4 produces a run-up that surpasses the observed one indicating that the best fitting model would be between model 3 and model 4 . 


\section{Maximum heights after $\mathbf{4 5}$ minutes of simulation (Les Saintes)}
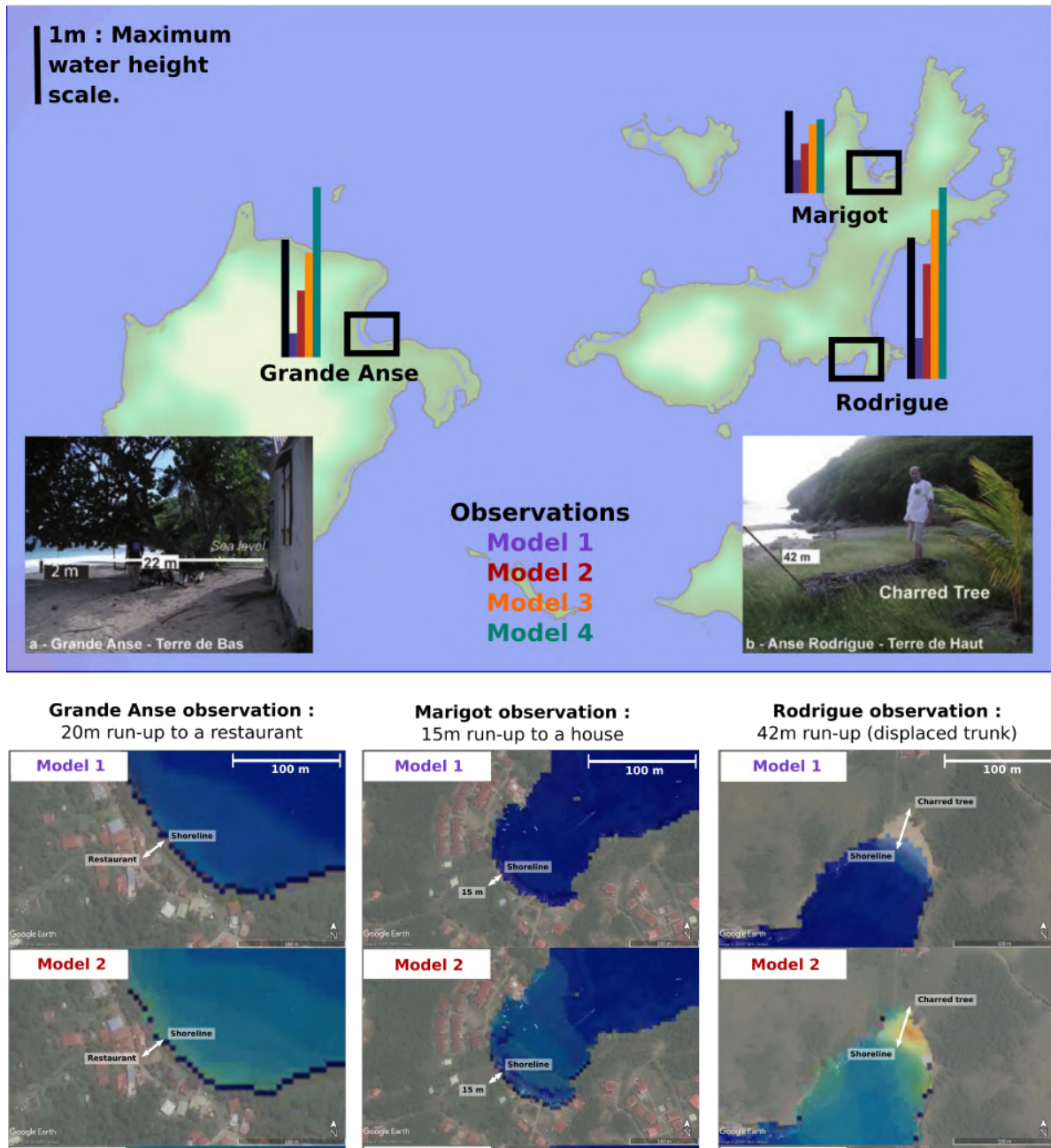

Rodrigue observation : $42 \mathrm{~m}$ run-up (displaced trunk)
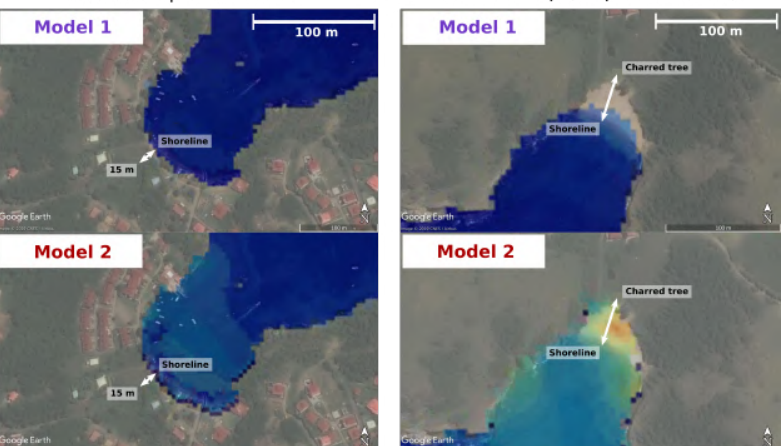

Model 2

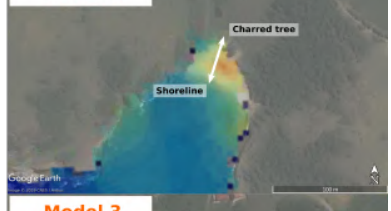

Model 3
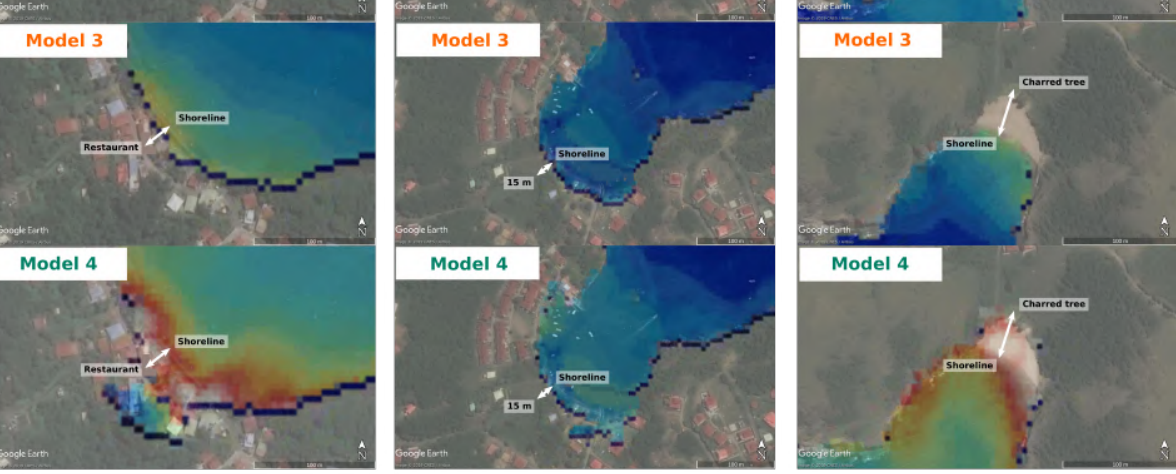

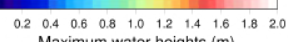

Fig. 10 Top : Les Saintes map with three places where important run-up were reported, the pictures of Grande Anse and Anse Rodrigue are from LeFriant et al. (2008). Bottom : 5m resolution maximum water height maps with activated run-up, for the three locations. Results from source models 1 to 4 are displayed from top to bottom. 


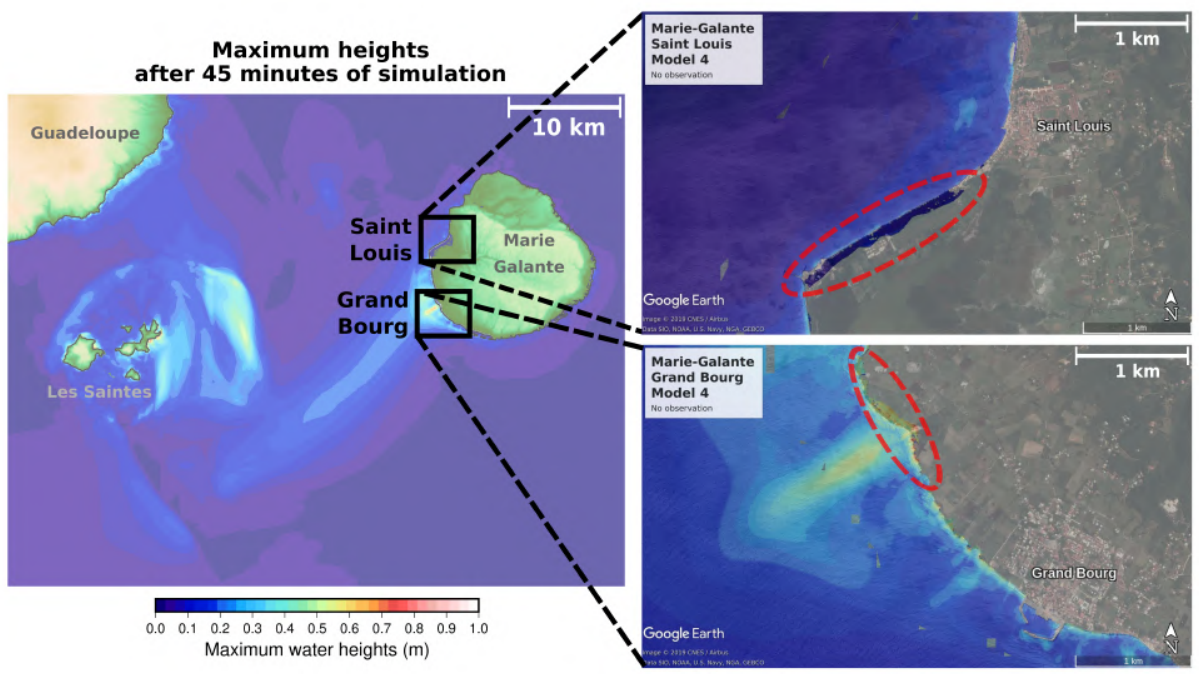

Fig. 11 Maximum water height maps of Saint-Louis and Grand-Bourg (Marie-Galante) simulated with the model 4 which generated important run-up indicated in the red circle.

\subsection{Marie-Galante results}

In Marie-Galante no wave or flood was reported after the earthquake and during the field surveys, the island is not very populated but the main city Grand-Bourg is located on the eastern coast in front of Roseau fault and could have been affected by the tsunami. The simulations all produce high tsunami waves toward Marie-Galante island and the analysis of the $5 \mathrm{~m}$ resolution Marie-Galante grid revealed important run-up in two main areas close to Grand-Bourg and Saint-Louis circled in red in Fig. 11. The topography of those areas is very low and they correspond to swampy areas where no one lives, which could explain the absence of observation. The flooded zones are extending $1 \mathrm{~km}$ along the coastline and $100 \mathrm{~m}$ inland, they represent a huge land surface and they stop at less than $1 \mathrm{~km}$ from the two cities of Grand-Bourg and Saint-Louis.

\section{Discussion}

6.1 Sensitivity to magnitude of coseismic vertical displacement

The results of model 1 simulation compared to models 2, 3 and 4 simulations clearly demonstrate that the generation of the tsunami with great enough wave heights in this area requires a fault rupture associated with the 2004 Les Saintes earthquake. The model 1 with its deeper rupture generates small water heights $(<50 \mathrm{~cm})$ that are inconsistent with the observations. The progressive increase of the surface-slip on models 2,3 and 4 correlates with the progressive reconciliation of results to observations. The analysis of the simulations at a regional level (in the coarse grid) favor the model 3 that generates maximum water heights closer to the observed one than model 4 ones, but the local analysis along Les Saintes coastline (high-resolution grids 
with run-up simulations) indicates that the best model would be closer to model 4 than model 3. Indeed, the tsunami wave probably reached higher levels than the heights where deposits and traces were found because it needs the energy to carry debris or to leave strong marks along the shore. The high-resolution run-up models are important because they highlight the actual characteristic of the wave on land. A model producing wave just high enough to flood the land with a run-up of a few centimeters thickness can not explain the displacement of important debris. However, a model that produces a consequent wave that will flood the land with the same run-up distance but with greater water thickness can better explain the observations. That is what emerges by comparing the run-up results of model 3 and model 4, model 4 presents more realistic floods considering the observations.

Model 3 corresponds to the maximum values of coseismic vertical slip measured at the seafloor (Escartin et al., 2019), and model 4 corresponds to vertical displacements that are $1 \mathrm{~m}$ higher than those observed (Table 2). So the best slip model is in between those two, meaning that the 2004 earthquake coseismic slip measured from the offset could have been underestimated and might be greater. However, the simulation tests did not result in a set of parameters respecting both the field data (tsunami observations, offset on the fault) and the magnitude $\mathrm{Mw}=6.3$ from seismic data. Indeed, the magnitude must exceed the value of 6.4 for the model to fit the surface rupture and to produce coherent water heights. It can indicate that, in addition to the coseismic slip values, other parameters should be considered like the rigidity of the seafloor, the intensity of the applied transfer function, or the magnitude estimation method. These differences between seismic moment and field data were previously observed for other earthquakes involving shallow rupture like the Mentawai event in 2011 (Newman et al., 2011) and the Ecuadorian Andes earthquake in 2010 (Champenois et al., 2017), highlighting questions that should be further explored.

\subsection{Transfer function}

The model 3NT (No Transfer Function) simulation presented in Fig. 12 where the initial sea surface deformation is the Okada's ground deformation translated to the sea surface, was performed in order to show the impact of the transfer function on the propagation and properties of the tsunami. The two maximum water height maps from the models 3 and 3NT (Fig. 12) present very different intensities with an almost $0.5 \mathrm{~m}$ wave height gap in some areas. The use of the transfer function in the vicinity of the source location (model 3) has a clear impact in the shape of the tsunami wave which is attenuated and smoothed. The synthetic signals extracted at an offshore tide gauge (Fig. 12 enhance this difference of sharpness between the two simulations with, at the wave peak (7 minutes), an amplitude twice bigger for the simulation without the transfer function. However, this gap seems to disappear when approaching the coast. Indeed, the signals extracted from different coastline locations in Les Saintes (Anse Muriers and Anse Rodrigue) present similar shapes and amplitudes. This phenomenon of attenuation differences from the sea to the coast is not well understood yet.

The use of a transfer function is more realistic and is justified for this study focused on small source parameters changes with high-resolution bathymetric grids. It should also be tested further for the study of tsunami waves in the offshore domain and in 
a near-field context. However, for coarser models, its impact on coastal amplitudes can be negligible and thus may not justify the additional computation time that it requires.

\subsection{Rupture homogeneity}

The model 3H (Homogeneous) presented in Fig. 13 is the homogeneous version of the model 3. The results presented in Fig. 13 show that maximum water heights are globally $0.5 \mathrm{~m}$ lower for the homogeneous model than for the heterogeneous one at same magnitude. This is consistent with the fact that a bigger part of the total slip is localized deeper in the homogeneous model than in the heterogeneous model and thus having less impact on surface deformation. The figures also show the differences obtained in the shape of the signals and the distribution of the maximum water heights. In the two synthetic tide gauge signals from Anse Murier and Anse Rodrigue, the homogeneous model's wave is approximately one minute early with respect to the heterogeneous one, it has a similar period, but presents less highfrequency oscillations. There are local variations in the signals but the last graphic shows that the regional distribution of the maximum water heights is impacted by this homogeneity. With the homogeneous model, Anse Rodrigue and the north of Terre de Bas (Grande Anse, Anse Pajot and Petite Anse) are less impacted by the tsunami while Baie de Marigot is proportionally more impacted. These variations at the coast between heterogeneous and homogeneous source model simulations highlight the need to take into account heterogeneous slip distribution in tsunami risk hazard assessment studies. High-frequency oscillations and variation in the water height distribution are evidence of the source's heterogeneities and can be determinant for the identification of source parameters. It is even more useful in a case where the tsunami signal is recorded and can be compared to the synthetics, which is unfortunately not the case here where at the moment of the event no tide gauges were working or active in the area.

The magnitude alone is not enough to analyze the intensity and characteristics of a tsunami. The heterogeneities of the source strongly impact the wave behavior, it can double its amplitude and affect the coasts in different ways.

\section{Conclusion}

The new models of the 2004 Les Saintes earthquake and tsunami presented in this paper bring further insight and understanding of the generation and propagation of the tsunami. This study was partly motivated by the recent results of the two oceanographic cruises (ODEMAR cruise in 2013 and SUBSAINTES cruises in 2017, Escartin et al., 2016) that imaged the Roseau fault scarp and revealed an important and unexpected offset up to $2.5 \mathrm{~m}$ of coseismic slip at the center of the fault and associated with the 2004 earthquake. These new data thus provide field constraints on displacement that are significantly higher than those estimated from models based on seismic inversion (Feuillet et al., 2011a), with maximum surface displacements of $<1 \mathrm{~m}$ instead. These new results suggest larger seafloor displacements with a possible impact on tsunami wave generation. Based on these results, we study the impact of the source heterogeneity and the transfer of displacement from the seafloor to the 


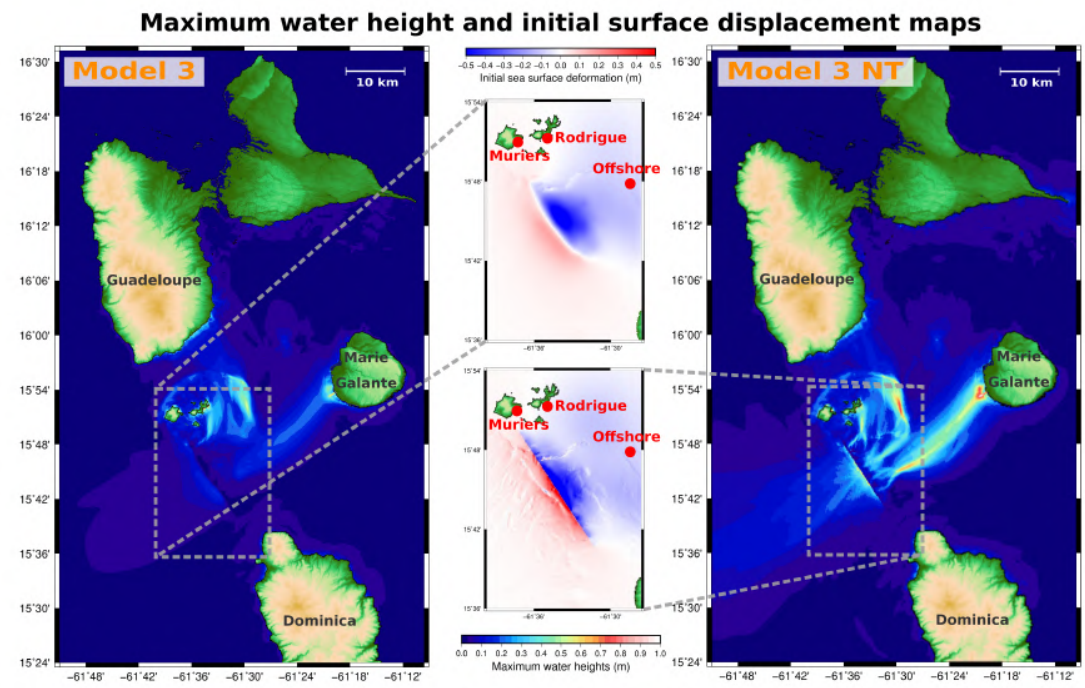

Synthetic tide gauges at three locations (red points on map)

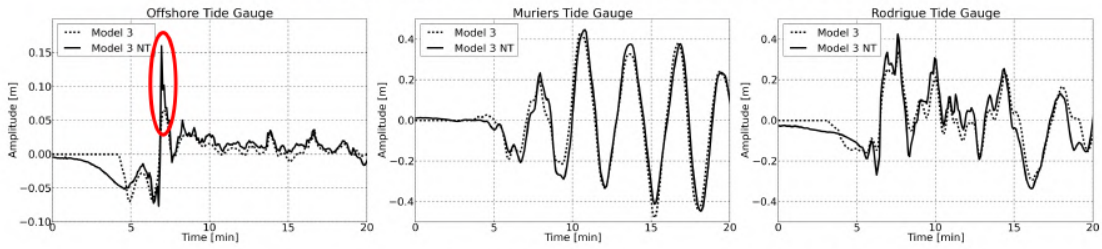

Maximum height value reached at each places of Les Saintes

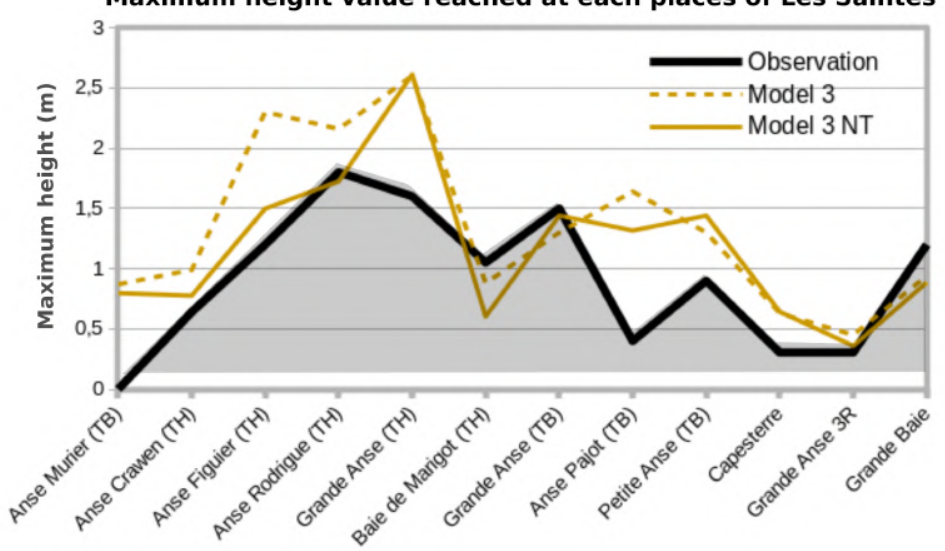

Fig. 12 Top: Maximum water heights maps and the associated initial sea surface displacement maps of model 3 and model 3NT. Middle: Three synthetic tide gauges signals of 20 minutes from the three sites indicated in red on the bathymetric map of the model 3NT (An offshore site, Anse Muriers and Anse Rodrigue). The signals are in dotted line for the model 3, in plain line for the model $3 \mathrm{NT}$ and the red circle indicates the strong amplitude difference at this peak between the two signals. Bottom: Maximum water height values that were reached at each site indicated previously in Fig. 8 extracted from model 3 (dotted orange line) and model $3 \mathrm{NT}$ (plain orange line) simulation and from the observations (black plain line). TB $=$ Terre de Bas (the western island of Les Saintes) and TH $=$ Terre de Haut (the eastern island of Les Saintes) 


\section{Fault models and maximum water height maps}
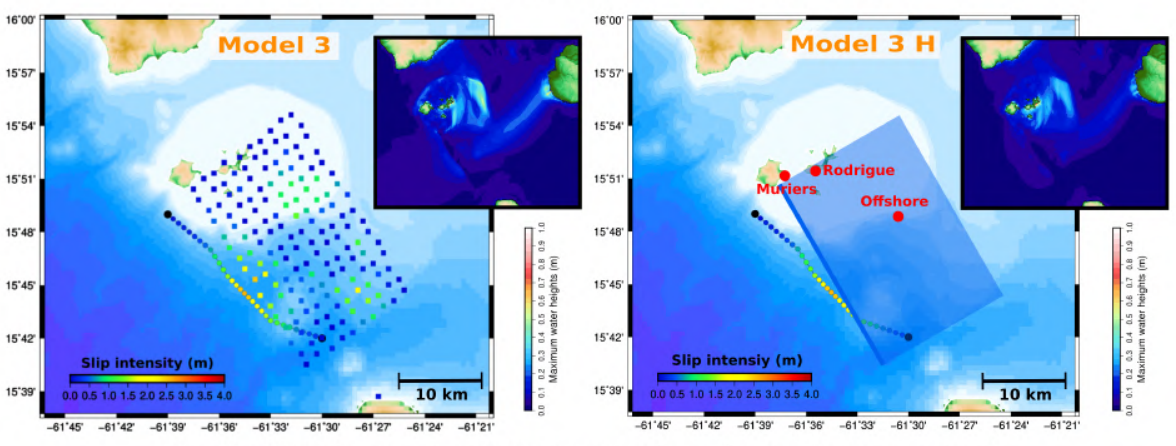

Synthetic tide gauges at three locations (red points on map)

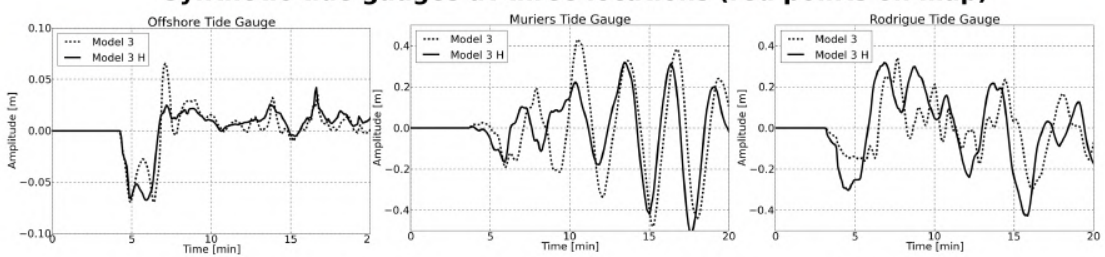

Maximum height value reached at each places of Les Saintes

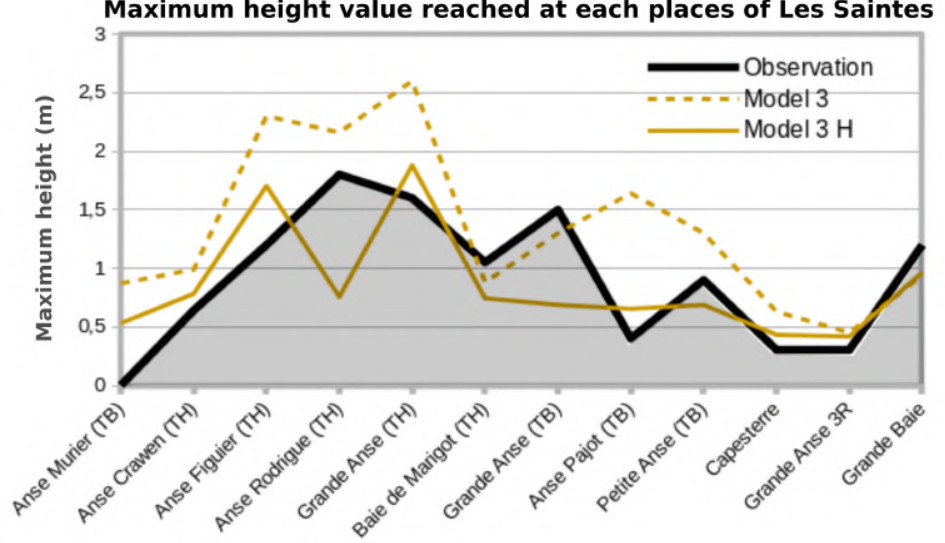

Fig. 13 Top: Bathymetric maps with the grid of the fault model for models 3 and $3 \mathrm{H}$ and their associated maximum water height map (right corner). The color scale of the grids corresponds to the slip magnitude associated to each segment of the fault (model 3 with 178 segments and model $3 \mathrm{H}$ with 1 segment), the line of colored circles represents the Roseau fault scarp with the color scale corresponding to the offset value observed during the ODEMAR and Subsaintes campaign (Escartin et al., 2017). Middle: Three synthetic tide gauges signals of 20 minutes from the three sites indicated in red on the bathymetric map of the model $3 \mathrm{H}$ (An offshore site, Anse Muriers and Anse Rodrigue). The signals are in dotted line for the model 3 and in plain line for the model 3H. Bottom: Maximum water height values that were reached at each site indicated previously in Fig. 8 extracted from model 3 (dotted orange line) and model $3 \mathrm{H}$ (plain orange line) simulation and from the observations (black plain line). TB = Terre de Bas (the western island of Les Saintes) and $\mathrm{TH}=$ Terre de Haut (the eastern island of Les Saintes) 
sea surface, processes that are generally difficult to constrain by lack of data on the surface rupture of faults underwater.

The other and complementary motivation for this work was the availability of high-resolution bathymetric and topographic grids (Litto3D from the SHOM) that greatly improves the results of simulations compared to previous model prediction calculated with much coarser grids and sources. This enables to follow the details of the propagation, to identify local amplification phenomena along the coral platforms or along the different coastlines, to provide more reliable water height distribution maps and to model realistic run-ups that can be directly compared to the observations on Les Saintes islands.

The simulations show that the tsunami path around the islands produces late arrivals of the strongest wave at the northern coast of Les Saintes. This explains why previous studies underestimated tsunami height at this same location, and show that the first tsunami arrivals are not always the strongest and most dangerous ones. The simulations also reproduce quite accurately the particularly small period and small wavelength of the tsunami that were reported by inhabitants of Les Saintes.

The introduction in the code of a transfer function of the initial deformation from the seafloor to the sea-surface was particularly adapted for such a shallow rupture in a deep sea environment. If the differences with and without it seem moderate, it can be significant when comparing high-resolution maps with a small amplitude gap between the models and trying to identify the best slip parameters. Also, with high-resolution terrain models as those used here, the impact in the model results of the source geometry, and in particular its heterogeneity, is significantly enhanced. In Les Saintes, an equivalent homogeneous source produces a different water height distribution than the heterogeneous source, and hence rupture geometry should be considered when identifying the best tsunami source parameters.

Finally, the comparison of the regional distribution of the water heights from different models favors a source that combines the deep rupture parameters estimated with the GPS and teleseismic data joint inversion and the shallow surface rupture parameters estimated with the 2013 and 2017 submarine field surveys. The sensitivity of the tsunami amplitude to shallow rupture processes is highlighted in this study, stressing that even a small magnitude event can be dangerously tsunamigenic depending on the nature of the seafloor deformation and earthquake rupture geometry. The simulations that best fit observations are those with a model fault slip both equal to, or larger than, the $2.5 \mathrm{~m}$ maximum offset observed on the Roseau fault scarp. There are two possible causes for this result. First, it may imply that the simulation underestimates the impact of fault slip at the seafloor on the generation of the tsunami wave indicating that a deeper work should be done on the choice of the rigidity parameters or the transfer function parameters. Second, the coseismic slip was actually greater than the measured one but not observed at the seafloor (e.g., limitations of observations, burial by sediments, etc.). Nevertheless, the results are consistent with the proposed coseismic origin for the rupture trace identified at the seafloor during the ODEMAR and SUBSAINTES cruises, and it is highly likely that aftershocks following the main event did not significantly contribute to the observed vertical displacement.

Differences in magnitude are still unsolved since the best fitting models correspond to $6.4<\mathrm{Mw}<6.5$ earthquakes while the 2004 earthquake was a $\mathrm{Mw}=6.3$, however, similar cases of surface rupture earthquakes have already been studied (Newman et al., 2011; Champenois et al., 2017) showing that it is not an isolated case. 
Interesting prospects to further study this 2004 event, include new W-phase seismic data inversion focusing on shallower parts of the fault to better fit field observations. This approach would help us understand if the energy generated by surface rupture is mostly missing from the seismic records, or if a tailored seismic inversion method is needed instead to identify it. The detection of such surface rupture is determinant in the process of tsunami alert since it is this part of the earthquake that mainly impacts the initial seafloor displacement and the potential generation of a tsunami. More generally, high-resolution mapping of other seafloor ruptures associated with tsunamigenic seismic events would provide us with a better understanding on their sources, and the transfer of seafloor deformation to tsunami wave generation at the sea surface.

Finally, the lack of tsunami records is a real limitation for our study, fortunately those last years have seen a great improvement in the update of the existent tide gauges and the installation of new station, with around thirty stations now operating throughout the Antilles subduction zone to help operational tsunami forecasting (e.g., Percival et al., 2015). This network will be useful for the detection and understanding of future events, however we should reflect on the DART buoys network expansion to the Lesser Antilles area, but DART system are very expensive. Two buoys are currently installed north of Puerto Rico and one in the Caribbean sea, but there is no buoys monitoring the subduction zone of the Lesser Antilles which is a lack considering its tsunamigenic potential. Others arising technologies would also provide a good opportunity to greatly improve tsunami-warning capabilities. For example, the data supplied by SMART cables would allow tsunami warning centers to more quickly validate and improve tsunami forecasts. SMART cable data could also greatly aid in the detection of tsunamis generated by or coupled with non-tectonic events such as landslides (e.g., Howe et al., 2019). The use of Global Navigation Satellite System (GNSS) displacement data in the near-field, originally installed to measure long-term tectonic motions, could also help improving tsumaniwarning capabilities. Over time, GNSS networks were upgraded with higher sample rate receivers and robust telemetry, allowing a faster computation of the earthquake magnitude using peak ground displacement scaling and earthquake source characteristics, such as focal mechanism and slip distribution, with a centroid moment tensor driven finite fault inversion utilizing coseismic offsets. Connecting such rapid source models to tsunami codes could allow producing a local forecast in the first 3-5 minutes after an earthquake (e.g., Crowell, et al., 2018; Kawamoto et al., 2019; Chen et al., 2020).

Acknowledgements This study benefitted from data acquired during the SUBSAINTES (doi: 10.17600/17001000) and ODEMAR (doi: 10.17600/13030070) cruises. We also acknowledge financial support to JE and NF from ANR SERSURF (ANR-17-CE31-0020) and ANR CARQUAKES (ANR-17-CE03-0006).

\section{Conflict of interest}

The authors declare that they have no conflict of interest. 


\section{References}

1. Armijo R., Pondard N., et al. Submarine fault scarps in the Sea of Marmara pull-apart (North Anatolian fault): implications for seismic hazard in Istanbul. Geochemistry Geophysics Geosystems 6:1-29, (2005)

2. Chen K., Z. Liu, and Y.T. Song. Automated GNSS and teleseismic earthquake inversion (AutoQuake Inversion) for tsunami early warning: Retrospective and real-time results. Pure and Applied Geophysics, 177(3), 1403-1423, (2020)

3. Crowell B. W., D. Melgar and J. Geng. Hypothetical real-time GNSS modeling of the 2016 Mw7.8 Kaikōura earthquake: Perspectives from ground motion and tsunami inundation prediction. Bulletin of the Seismological Society of America, 108(3B), 1736-1745, (2018)

4. Bazin, S., et al. The 2004-2005 Les Saintes (French West Indies) seismic aftershock sequence observed with ocean bottom seismometers, Tectonophysics, doi:10.1016/j.tecto.2010.04.005, (2010)

5. Beauducel F., et al. , The Mw 6.3 earthquake of Les Saintes (Guadeloupe) on November 21, 2004, paper presented at European Seismological Commission Annual Workshop, Int. Assoc. of Volcanol. and Chem. of the Earth's Inter., Saint-Claude, Guadeloupe, (2005)

6. Cara M. BCSF. Séisme des Saintes (Guadeloupe) du 21 novembre 2004. Rapport de recherche, BCSF-RENASS, hal-01833992, (2005)

7. Champenois, J., Baize, S., Vallee, M.,Jomard, H., Alvarado, A. P., Espin, P.,... Audin, L. Evidences of surface rupture associated with alow-magnitude (Mw5.0) shallow earthquake in the Ecuadorian Andes.Journal of Geophysical Research: Solid Earth,122, 8446-8458. https://doi.org/10.1002/2017JB013928. (2017)

8. Cordrie L., Javier E., Audrey G., Nathalie F., Philippe H. Simulation of the 2004 tsunami of Les Saintes in Guadeloupe (Lesser Antilles). OCEANS 2019 - Marseille, Jun 2019, Marseille, France. pp.1-9, doi: 10.1109/OCEANSE.2019.8867447, hal-02332675, (2019)

9. Demets C., P. Jansma, G. Mattioli, T. Dixon, F. Farina, R. Bilham, E. Calais, P. Mann. GPS geodetic constraints on Caribbean-NorthAmerica Plate Motion. Geophysical Research Letters. 27. 437-440.10.1029/1999GL005436. (2000)

10. Escartin J., N. Feuillet, A. Lefriant, SUBSAINTES Cruise, doi: 10.17600/17001000, (2017)

11. Escartin J., F. Leclerc, J. Olive, C. Mevel, M. Cannat, S. Petersen, N. Augustin, N. Feuillet, C. Deplus, A. Bezos, et al. First direct observation of coseismic slip and seafloor rupture along a submarine normal fault and implications for fault slip history: Earth and Planetary Science Letters, v. 450, p. 96-107, doi: 10.1016/j.epsl.2016.06.024, (2016)

12. Escartin J., J. Billant, F. Leclerc, J.A. Olive, K. Istenic, N. Gracias, et al., Seafloor rupture of a normal fault: geometry, displacement, and links between erosion/sedimentation and seismicity, Geophysical Research Abstracts, Vol. 21, EGU2019-14799-1, (2019)

13. Feuillet N., Sismotectonique des Petites Antilles: Liaison entre activité sismique et volcanique, Ph.D. thesis, 283 pp., Univ. Paris VII, Paris, (2000)

14. Feuillet N., I. Manighetti, P. Tapponnier, and E. Jacques. Arc parallel extension and localization of volcanic complexes in Guadeloupe, Lesser Antilles, J. Geophys. Res., 107(B12), 2331, doi:10.1029/2001JB000308, (2002)

15. Feuillet N., F. Beauducel, E. Jacques, P. Tapponnier, B. Delouis, B. Delouis, S. Bazin, M. Vallée and G. C. P. King. The Mw $=6.3$, November 21, 2004, Les Saintes earthquake (Guadeloupe): Tectonic setting, slip model and static stress changes,. Journal of Geophysical Research : Solid Earth, American Geophysical Union, 116 (B10), pp.B10301, doi : 10.1029/2011JB008310, (2011)(a)

16. Feuillet N., F. Beauducel, and P. Tapponnier. Tectonic context of moderate to large historical earthquakes in the Lesser Antilles and mechanical coupling with volcanoes, J. Geophys. Res., doi:10.1029/2011JB008443, (2011)(b)

17. Fujiwara, T. et al. The 2011 Tohoku-Oki Earthquake: Displacement Reaching the Trench Axis. Science 334, 1240, (2011)

18. Glimsdal, S., Pedersen, G. K., Harbitz, C. B., and Lovholt, F.: Dispersion of tsunamis: does it really matter ?, Nat. Hazards Earth Syst. Sci., 13, 1507-1526, https://doi.org/10.5194/nhess-13-1507-2013, (2013)

19. Hébert H., A. Sladen, and F. Schindelé. Numerical modeling of the great 2004 Indian Ocean tsunami: focus on the Mascarene Islands. Bulletin of the Seismological Society of America, 97(1A), (2007)

20. Hébert H., D. Reymond, Y. Krien, et al. The 15th August 2007 Peru earthquake and tsunami: influence of the source characteristics on the tsunami heights. Pure and Applied Geophysics, 166, 211-232, doi:10.1007/s00024-008-0439-0, (2009) 
21. Heinrich P., F. Schindele, S. Guibourg and P.F. Ihmle. Modeling of the February 1996 Peruvian Tsunami. Geophysical Research Letters, 25(14), 2687-2690, (1998)

22. Howe B. M., B.K. Arbic, J. Aucan, C. Barnes, N. Bayliff, N. Becker, F. Landerer et al. SMART cables for observing the global ocean: science and implementation. Frontiers in Marine Science, 6, 424, (2019)

23. Istenic, K., N. Gracias, A. Arnaubec, J. Escartín, and R. García, Automatic scale estimation of structure from motion based 3D models using laser scalers in underwater scenarios, ISPRS Journal of Photogrammetry and Remote Sensing, 159, 13-25, doi: 10.1016/j.isprsjprs.2019.10.007, (2020)

24. Istenic, K., N. Gracias, A. Arnaubec, J. Escartín, and R. García, Scale accuracy evaluation of image based 3D reconstruction strategies using laser photogrammetry, Remote Sensing, 11(18), 2093, doi:10.3390/rs11182093, (2019)

25. Kajiura K., The leading wave of a tsunami, Bull. Earthq. Res. Ins., 41, 545-571, (1963)

26. Kawamoto S., S. Abe, T. Miyazaki, H. Muramatsu, N. Takamatsu, Y. Ohta, T. Nishimura et al. Real-time coseismic fault model estimation based on RTK-GNSS analysis for rapid tsunami simulations. In Geophysical Research Abstracts (Vol. 21), (2019)

27. Kodaira S., T. No, Y. Nakamura, T. Fujiwara, Y. Kaiho, S. Miura, N. Takahashi, Y. Kaneda and A. Taira. Coseismic fault rupture at the trench axis during the 2011 Tohokuoki earthquake, Nature Geoscience, Vol. 5, 646-650, doi:10.1038/ngeo1547, (2012)

28. Newman, A. V., Hayes, G., Wei, Y., and Convers, J. The 25 October 2010 Mentawai tsunami earthquake, from real-time discriminants, finite-fault rupture, and tsunami excitation, Geophys. Res. Lett., 38, L05302, doi:10.1029/2010GL046498. (2011)

29. Lander J.F., L.S. Whiteside, and P.A. Lockridge. A brief history of tsunami in the Caribbean Sea. Science of Tsunami Hazards, v. 20, 57-94, (2002)

30. Le Friant A., P. Heinrich, and G. Boudon. Field survey and numerical simulation of the 21 November 2004 tsunami at Les Saintes (Lesser Antilles), Geophys. Res. Lett., 35, L12308, doi:10.1029/2008GL034051, (2008)

31. Leclerc F., Feuillet N., Cabioch G., Deplus C., Lebrun J.F., BATHYSAINTES cruise scientific party, Bazin S., Beauducel F., Boudon G., LeFriant A., De Min L. and Melezan D. The Holocene drowned reef of Les Saintes plateau as witness of a long-term tectonic subsidence along the Lesser Antilles volcanic arc in Guadeloupe: Marine Geology, V. 355, P.115-135, https://doi.org/10.1016/j.margeo.2014.05.017, (2014)

32. Leclerc F., N. Feuillet, and C. Deplus. Interactions between active faulting, volcanism, and sedimentary processes at an island arc: Insights from Les Saintes channel, Lesser Antilles arc: Geochemistry, Geophysics, Geosystems, v. 17, no. 7, p.2781-2802, doi:10.1002/2016GC006337, (2016)

33. Leclerc et Feuillet. Quaternary coral reef complexes as markers of long-term subduction-induced subsidence. Geosphere, Geological Society of America, 2019, doi:10.1130/GES02069.1. hal-02361011, (2019)

34. Okada Y. Surface deformation due to shear and tensile faults in a half-space. Bulletin of the Seismological Society of America, 75(4):1135, (1985)

35. Pawlowicz R., B. Beardsley, and S. Lentz, "Classical Tidal Harmonic Analysis Including Error Estimates in MATLAB using T-TIDE", Computers and Geosciences, 28, 929-937, (2002)

36. Paulatto M., M. Laigle, A. Galve et al. Dehydration of subducting slow-spread oceanic lithosphere in the Lesser Antilles. Nat. Commun. 8, 15980 doi: 10.1038/ncomms15980, (2017)

37. Percival D.B., D. Denbo, M.C. Eblé, E. Gica, P.Y. Huang, H.O. Mofjeld, E.I. Tolkova et al. Detiding DART buoy data for real-time extraction of source coefficients for operational tsunami forecasting. Pure and Applied Geophysics, 172(6), 1653-1678, (2015)

38. Poupardin A., P. Heinrich, H. Hébert, F. Schindelé, A. Jamelot, D. Reymond, H. Sugioka. Traveltime delay relative to the maximum energy of the wave train for dispersive tsunamis propagating across the Pacific Ocean: the case of 2010 and 2015 Chilean Tsunamis. Geophysical Journal International. 214. 10.1093/gji/ggy200, (2018)

39. Reid H.F. and Taber S. The Virgin Islands earthquakes of 1867-1868, Bull. Seismol. Soc. Am., 10, 9-30, (1920)

40. Reymond D., E. Okal, H. Hébert and M. Bourdet. Rapid forecast of tsunami wave heights from a database of pre-computed simulations, and application during the 2011 Tohoku tsunami in French Polynesia, Geophys. Res. Lett., 39, L11603, doi:10.1029/2012GL051640, (2012) 
41. Sainte-Claire Deville M.Ch. Observations sur le tremblement de terre éprouvé è la Guadeloupe le 8 février 1843, (1843)

42. Sainte-Claire Deville M.Ch. Sur le tremblement de terre du 18 novembre 1867 aux Antilles. Comptes Rendus, Acad. Sci., Paris, v. 65, 1110-1114, (1867)

43. Salichon J., A. Lemoine, and H. Aochi. Validation of teleseismic inversion of the 2004 M-w 6.3 Les Saintes, Lesser Antilles, earthquake by 3D finite-difference forward modeling, Bull. Seismol. Soc. Am., 99, 3390-3401, (2009)

44. Schindelé F., A. Gailler, H. Hébert et al. Implementation and Challenges of the Tsunami Warning System in the Western Mediterranean. Pure Appl. Geophys. 172, 821-833, doi:10.1007/s00024-014-0950-4, (2015)

45. Shepherd J.B. Tsunami hazard in the Eastern Caribbean. Workshop on Volcanic and Seismic Hazards in the Eastern Caribbean (May 28 - June 1, 2001), (2001).

46. Shepherd J.B. and L.L. Lynch. An earthquake catalogue for the Caribbean, Part I., The pre-instrumental period, 1502-1990. Paper presented to the Steering Committee, Latin American and Caribbean Seismic Hazard Programme, April, 60 pp. (1992)

47. Stein S., J. F. Engeln, and D. A. Wiens. Subduction seismicity and tectonics in the lesser Antilles arc, J. Geophys. Res., 87, 8642-8664, (1982)

48. Tsuji T., K. Kawamura, T. Kanamatsu, T. Kasaya, K. Fujikura, Y. Ito, T. Tsuru, M. Kinoshita. Extension of continental crust by anelastic deformation during the 2011 Tohokuoki earthquake: the role of extensional faulting in the generation of a great tsunami. Earth Planet. Sci. Lett., 364, pp. 44-58, (2013)

49. Zahibo N., E. Pelinovsky, E. Okal, A. Yalçiner, C. Kharif, T. Talipova and A. Kozelkov. The earthquake and tsunami of November 21, 2004 at Les Saintes, Guadeloupe, Lesser Antilles, Science of Tsunami Hazards, Vol. 23, No. 1, 25-39, (2005)

50. Wells D.L. and K.J. Coppersmith. New empirical relationships among magnitude, rupture length, rupture width, rupture area, and surface displacement. Bulletin of the Seismological Society of America, 84(4):974, (1994) 